\title{
Olfactory Sensory Neurons Are Trophically Dependent on the Olfactory Bulb for Their Prolonged Survival
}

\author{
James E. Schwob, Karen E. Mieleszko Szumowski, and Audrey A. Stasky \\ Department of Anatomy and Cell Biology and The Clinical Olfactory Research Center, SUNY Health Science Center, \\ Syracuse, New York 13210
}

In most neural systems, developing neurons are trophically dependent on contact with their synaptic target for their survival and for some features of their differentiation. However, in the olfactory system, it is unclear whether or not the survival and differentiation of olfactory sensory neurons depend on contact with the olfactory bulb (normally the sole synaptic target for these neurons). In order to address this issue, we examined neuronal life-span and differentiation in adult rats subjected to unilateral olfactory bulb ablation at least 1 month prior to use. Life-span of a newly generated cohort of olfactory neurons was determined by labeling them at their "birth" via the incorporation of ${ }^{3} \mathrm{H}$-thymidine. In the absence of the bulb, neurons are continually produced at a twofold greater rate. However, the epithelium on the ablated side is thinner, indicating that average neuronal life-span must be reduced in the targetless eplthelium. Indeed, nearly $90 \%$ of the labeled neurons disappear from the bulbectomized side between $5 \mathrm{~d}$ and 2 weeks of neuronal age. Moreover, on electron microscopic examination, olfactory axons are degenerating in large numbers on the ablated side. Since labeled neurons migrate apically through the width of the epithelium during this same period, it appears that most, if not all, neurons on the ablated side have a life-span on the order of $\mathbf{2}$ weeks or less. In contrast, there is a more moderate degree of neuronal loss on the unoperated side of the same animals during the first 2 weeks after tracer injection, and that occurs while the neurons are concentrated in the deeper half of the epithelium, suggesting that there is a preexisting population of neurons in the control epithelium that does not die during this period. Likewise, degenerating axons are much less frequent on the unoperated side. We conclude that life-span is significantly shorter for olfactory neurons born in the targetless epithelium and that olfactory neurons are trophically dependent on the presence of the bulb for their prolonged survival.

\footnotetext{
Received Oct. 10, 1991; revised Mar. 12, 1992; accepted May 4, 1992

We thank Dr. Frank Margolis for his generous gift of antiserum to olfactory marker protein, and Dr. Rory Curtis for his generous gift of antiserum to GAP43. Special thanks go to Dr. Karina Meiri for her gift of monoclonal antibodies to GAP-43 and for her helpful and patient criticisms of the manuscript, and to Dr. Steven Youngentob for his advice on the manuscript. This work was supported by NIH Grants P01 DC 00220 and R29 DC 00467, and by a Basil O'Connor Starter Scholar Award from the March of Dimes Birth Defects Foundation. J.E.S. is an Alfred P. Sloan Research Fellow.

Correspondence should be addressed to James E. Schwob, M.D., Ph.D., Department of Anatomy and Cell Biology, SUNY Health Science Center, 750 East Adams Street, Syracuse, NY 13210.

Copyright $(\mathcal{C} 1992$ Society for Neuroscience $0270-6474 / 92 / 123896-24 \$ 05.00 / 0$
}

Neuronal differentiation in the absence of the bulb was assessed according to ultrastructural criteria and the pattern of protein expression using antisera to the growth associated protein GAP-43 and the olfactory marker protein. By both measures, most neurons in the epithelium on the bulbectomized side, but not all, are immature. Despite the relative preponderance of immature neurons, we were unable to demonstrate any delay in the time course of neuronal differentiation in experiments combining thymidine birthdating with an immunohistochemical assessment of maturation. Indeed, the increase in neurogenesis and the accelerated demise of neurons on the ablated side can account for the greater number of immature neurons and the lesser number of mature neurons on this side, respectively. Therefore, the data from the analysis of the differentiation and survival of olfactory neurons born after bulbectomy are most consistent with the hypothesis that the target does not induce or stimulate neuronal differentiation, but rather the bulb serves to stabilize the population of mature olfactory neurons by providing the trophic support necessary for their survival. This trophic mechanism, in combination with influences on the rate of neurogenesis (e.g., the stimulation associated with retrograde neuronal degeneration), would help regulate the size of the neuronal population and its stability.

The olfactory epithelium is unique in the mammalian nervous system in its ability to recover from injury; even in the adult, neurons that die can be replaced by the birth of new neurons that arise via the mitotic division of basal cells residing in the depths of the epithelium (Monti Graziadei and Graziadei, 1979). Moreover, neurogenesis is ongoing even in "normal" animals housed in the relatively protected environment found in the laboratory (Moulton et al., 1970; Graziadei and Monti Graziadei, 1978). Because most of a cohort of neurons born at a particular moment in the life of the unmanipulated adult animal disappear from the epithelium within roughly 1 month after becoming postmitotic (as documented by counts following pulse injections of ${ }^{3} \mathrm{H}$-thymidine), it has been suggested that olfactory neurons have a fixed, finite life-span that is intrinsically determined (Moulton et al., 1970; Graziadei and Monti Graziadei, 1978). However, evidence has begun to accumulate that olfactory neuronal life-span is affected by the environment to which the epithelium is exposed (reviewed by Farbman, 1990).

The concept that life-span for olfactory neurons is intrinsically fixed and finite differs markedly from our understanding of neuronal life cycle in other parts of the nervous system, where the continued health and/or survival of a neuron is commonly de- 
pendent on the trophic interactions between it, the target that it innervates, and/or the afferents that innervate it (Purves, 1988). In the case of the olfactory system, the status of the sensory neurons is known to be affected by ablation of its CNS target, the olfactory bulb. As described by Le Gros Clark (1951), ablation of the bulb acutely causes widespread retrograde neuronal death. In the chronic absence of the bulb, the epithelium remains thinner than normal, and there is a marked reduction in the number of olfactory neurons that express the olfactory marker protein (OMP) (Monti Graziadei, 1983; Verhaagen et al., 1990). Furthermore, there is a concomitant increase in the number of olfactory neurons that express the growth-associated protein GAP-43 after bulbectomy (Verhaagen et al., 1990). Likewise, blocks of epithelium harvested from embryos and maintained in vitro in the absence of the bulb show fewer OMP-containing neurons and fewer dendritic knobs than does the epithelium maintained in the presence of the bulb (Chuah and Farbman, 1983; Chuah et al., 1985). The exact nature of the influence of the bulb on the neurons of the olfactory epithelium remains uncertain. Either the olfactory bulb actively promotes neuronal differentiation, or its presence may simply allow neurons to survive long enough to permit full neuronal differentiation.

The purpose of this study was to examine closely the life-span and differentiation of neurons in the olfactory epithelium of rats that were born in the absence of their synaptic target as a consequence of unilateral olfactory bulbectomy by utilizing pulse labeling with thymidine analogs, electron microscopic examination, and immunohistochemical evaluation. We have confined our analysis to survival times after ablation that exceed 1 month, at which time acute retrograde degeneration has ceased, and the epithelium has stabilized in thickness (Costanzo and Graziadei, 1983). Our data suggest that life-span is foreshortened in the epithelium on the bulbectomized side and, therefore, that the olfactory neurons are trophically dependent on contact with their target for their survival. In contrast, we have been unable to adduce any evidence that the normal course of differentiation is substantially delayed or disrupted in the absence of the target. This result brings the olfactory system more in line with what is known of differentiation and death in other neuronal populations of the PNS and CNS, where trophic interactions are a general feature of neural development.

These results have been previously presented in preliminary form (Schwob et al., 1988; Schwob and Szumowski, 1989).

\section{Materials and Methods}

Animals. Outbred Sprague-Dawley rats were obtained from a barrierisolated facility (Taconic Farms) and maintained in a temperature and humidity controlled vivarium. The animals showed no external signs of chronic rhinitis, and the epithelium was free from disease by microscopic examination. They were unilaterally bulbectomized at 2-3 months of age or were used as age-matched unoperated normals.

Olfactory bulbectomy. After induction of anesthesia with chloral hydrate $(420 \mathrm{mg} / \mathrm{kg}$, i.p.), the right olfactory bulb was exposed via a dorsal craniotomy and was ablated by suction. Care was taken to avoid damaging the contralateral (i.e., left) olfactory bulb. The ablation cavity was packed with Oxycel and the skin sutured. The degree of lesion was visually and microscopically verified; in all cases it was either complete or supercomplete (extending into the olfactory peduncle). After recovery from anesthesia, the animals were returned to the vivarium until they were used at some time between 1-9 months after surgery.

Injections of thymidine analogs. Either bromodeoxyuridine (BrdU; Kodak Chemicals) or ${ }^{3} \mathrm{H}$-thymidine ( ${ }^{3} \mathrm{H}$-thy; $85 \mathrm{Ci} / \mathrm{mmol}$; Amersham) was used to label cells in the S-phase of the cell cycle as follows. Bulbectomized and age-matched normal animals were anesthetized with chloral hydrate and the femoral vein exposed. In those rats that received BrdU, a dose of $20 \mu \mathrm{g} / \mathrm{gm}$ body weight (bw) dissolved in Dulbecco's Modified Eagle's Medium at a concentration of $20 \mathrm{mg} / \mathrm{ml}$ was injected intravenously as a single bolus. In other animals, ${ }^{3} \mathrm{H}$-thy was administered intravenously at $3 \mu \mathrm{Ci} / \mathrm{gm}$ bw. The dosage of ${ }^{3} \mathrm{H}$-thy is well below the tracer dose of $0.5 \mu \mathrm{g} / \mathrm{gm}$ bw, while that of BrdU is slightly in excess of the tracer dose of $5 \mu \mathrm{g} / \mathrm{gm}$ bw (Boswald et al., 1990). There is no evidence that either BrdU or ${ }^{3} \mathrm{H}$-thy is toxic at these doses (Denham, 1967; Skalko et al., 1971), and both are compatible with longterm labeling of neurons (Miller and Nowakowski, 1988). In both cases, tracer administered by this route is cleared from the blood in less than $1 \mathrm{hr}$ (Kriss and Revesz, 1962; Nowakowski and Rakic, 1974). Rats were allowed survivals of $2 \mathrm{hr}, 5 \mathrm{~d}$, or 2 weeks after injection of the tracer before death. A total of three bulbectomized rats were injected with ${ }^{3} \mathrm{H}$ thy per survival time. Three bulbectomized rats and three age-matched, unmanipulated normals were killed $2 \mathrm{hr}$ after injection of BrdU. The survival times were chosen to identify and quantify the proliferating basal cells ( $2 \mathrm{hr}$ survival), the cohort of neurons born within one or two cell divisions of the incorporation of label by the basal cells $(5 \mathrm{~d}$ survival), and the relative survival of that cohort as neuronal maturation proceeds ( 2 week survival) both in the presence and the absence of the olfactory bulb.

At the time of death, rats were perfused intracardially with Bouin's fluid and postperfusion fixed for a minimum of $4 \mathrm{hr}$. The tissue harvested from rats injected with ${ }^{3} \mathrm{H}$-thymidine was decalcified in a formic acid-sodium citrate solution and cmbedded in paraffin for coronal sectioning at 2 or $4 \mu \mathrm{m}$. Sections were dipped in NTB-2 autoradiographic emulsion (Kodak) diluted 1:4 in water using a published procedure (Rogers, 1979), in some cases after immunostaining (see below). The autoradiographs were exposed for 3 weeks before developing with $D$ 19. The olfactory epithelia and bulbs from those rats injected with BrdU were sectioned at $8 \mu \mathrm{m}$ with a cryostat microtome. BrdU-labeled cells were identified by immunostaining as described below.

Immunohistochemistry. The growth-associated protein GAP-43 was visualized using a rabbit polyclonal antiserum (Curtis et al., 1991) that recognizes both phosphorylated and nonphosphorylated forms of the protein (K. F. Meiri and J. E. Schwob, unpublished results). OMP was visualized with a polyclonal goat antiserum to OMP (Graziadei, 1977; Margolis, 1985). BrdU was visualized using a mouse monoclonal antiBrdU antibody that was obtained commercially (Becton-Dickinson Immunochemistry).

Avidin-biotinylated HRP or fluorescence visualization of bound primary antibody was performed as previously described (Meiri et al., 1991), with two exceptions. First, tissue to be stained with anti-BrdU was treated in $100 \%$ ethanol for $20 \mathrm{~min}$ and then with $6 \mathrm{~N} \mathrm{HCl}$ for 30 min. Subsequently, sections were neutralized by two washes in $0.1 \mathrm{M}$ sodium borate buffer, $\mathrm{pH} 8.5$, rinsed in phosphate-buffered saline (PBS), and blocked prior to application of the primary antibody. Second, double immunofluorescent labeling with anti-OMP and anti-GAP-43 was accomplished by incubating the tissue with both antibodies simultaneously, followed by biotinylated anti-rabbit and Texas red-conjugated anti-goat secondary antibodies raised in donkeys (Jackson ImmunoResearch, West Grove, PA), and finally fluoresceinated avidin D (Vector Laboratories). The double-labeled sections were coverslipped in CitiFluor AF1 mountant (CitiFluor Ltd., London, UK) and photographed using a Nikon Microphot equipped with B2-E and G2-A filters. Control experiments demonstrated that the secondary antibodies exhibited no cross-reactivity to the nonintended primary; furthermore, there was no bleedthrough of the signals between fluorescent channels with this set of filters.

Counting procedures. Five different analyses were performed at the light microscopic level. First, we counted ${ }^{3} \mathrm{H}$-thymidine-labeled cells on autoradiographed sections that had been counterstained with hematoxylin. The sections were examined at $40 \times$, and cells were counted as labeled if the number of autoradiographic grains over the nucleus was greater than 10; this degree of labeling is approximately $10 \times$ background. In each of the three cases at the three survival times, we sampled seven equally spaced levels of the epithelium from near its rostral limit to the region of the mucosa ventral to the olfactory bulb, and we counted all parts of the olfactory epithelium that were present at the sampled levels. At each of the seven levels, the sections that were examined were chosen to be roughly equivalent among all animals. Any slight differences in the extent of the epithelium between the two sides were corrected by determining the length of epithelium and dividing the raw counts by the length measurement to yield a labeling index. The labeling 
index was then used to compare the two sides in the same animal and among the animals of a particular group. In addition to these counts, the depth of labeled neurons along the basal-apical axis of the septal epithelium was determined for bulbectomized rats killed at $5 \mathrm{~d}$ and 2 weeks after labeling with ${ }^{3} \mathrm{H}$-thy; this measure was recorded in tandem with the thickness of the neuronal zone of the epithelium, which is defined here as the distance from the basement membrane to the deep edge of the supporting cell layer. The ratio of neuronal depth to thickness of the neuronal zone was used to compare the relative vertical extent of labeled neurons in the epithelium on the ablated versus control sides.

Second, we counted anti-BrdU-labeled cells on immunoperoxidasestained cryostat sections. Because there was no tissue background associated with the immunoperoxidase staining for BrdU, it was quite easy to distinguish labeled from nonlabeled nuclei. Otherwise, the procedures used for the BrdU counts were the same as were described above.

Third, we counted anti-GAP-43-labeled neurons on immunofluorescent-stained sections from animals that had been labeled with ${ }^{3} \mathrm{H}$ thymidine and allowed to survive for $2 \mathrm{hr}$. In this case as well, we examined seven equally spaced sections from rostral to caudal in the epithelium, and we counted the number of fluorescently labeled neurons along the full traverse of the epithelium at any particular level. Care was taken to count only those labeled neurons that could be clearly identified. As a help in identifying cells, the sections were also fluorescently counterstained with the Hoechst nuclear dye bisbenzamide (H33258, Polysciences) before being coverslipped.

Fourth, we counted autoradiographically labeled cells on sections that had been labeled with either anti-GAP-43 or anti-OMP and visualized by avidin-biotinylated HRP; in this case, cells were identified as thymidine labeled alone, or as doubly labeled with both ${ }^{3} \mathrm{H}$-thy and antibody. The criteria for thymidine labeling and the procedure followed were the same as for the counts of the tracer-labeled cells alone, except that the section was examined with a $60 \times$ oil immersion lens to improve visualization of the autoradiographic grains against the peroxidase labeling of the neurons.

Fifth, we counted the neurons that were doubly stained on photographs of $2 \mu \mathrm{m}$ sections incubated with both anti-GAP-43 and antiOMP; on this same set of photographs the total number of neurons that were labeled with anti-GAP-43 was also determined. A neuron was considered to be labeled by a marker if its perikaryon "stood out" by comparison with either basal or supporting cells. Such a criterion results in the inclusion of both lightly and heavily labeled neurons. The requirement to use photographs to identify doubly labeled cells reliably proscribes sampling of the epithelium as extensively as for the other analyses. Nonetheless, in this case as well, several regions of the epithelium were examined, including the epithelium lining the nasal septum, that lining both the ecto- and endoturbinates, and that lining the lateral and ventral cul de sacs. A total length of epithelium of $3 \mathrm{~mm}$ or more was counted in each of four bulbectomized animals.

Electron microscopic evaluation. For transmission electron microscopy (TEM), unilaterally bulbectomized rats were killed at survival times of $4 \mathrm{~d}(n=2), 6 \mathrm{~d}(n=2), 4$ weeks $(n=2), 8$ weeks $(n=2)$, and 16 weeks $(n=1)$. Rats were perfused intracardially with $50 \mathrm{ml}$ of cold PBS (forced by syringe) followed by $350 \mathrm{ml}$ of cold fixative ( $2 \% \mathrm{glu}$ taraldehyde and $0.6 \%$ paraformaldehyde in $0.06 \mathrm{M}$ sodium cacodylate buffer, pH 7.2) using a gravity-fed perfusion apparatus (Graziadei and Monti Graziadei, 1979). Blocks from closely matched areas of the epithelium were harvested from both the septum and turbinates. The tissue was postfixed in 1\% osmium tetroxide for $1 \mathrm{hr}$, dehydrated, and embedded in Araldite. Thin (gray/silver) sections were deposited onto Formvar-coated grids, stained with uranyl acetate and lead citrate, and examined on a JEOL JEM 100 CXII TEM at 60 and $80 \mathrm{kV}$.

Olfactory knobs were counted and classified as multiciliated or not on both ablated and control sides in two animals with 4 week survivals and one with a 16 week survival after unilateral bulbectomy. Between 0.5 and $2.0 \mathrm{~mm}$ of epithelium was examined from two to four matched sites per side. The criterion for classifying a knob as multiciliated was the presence of two or more large cilia emerging from the knob in the plane of the section. Almost certainly, this is an underrepresentation of the number of cilia elaborated by a single knob. Nonetheless, it is a rcasonable measure for comparing the relative claboration of cilia by knobs on the two sides, and it correlates well with observations made using the scanning electron microscope (SEM) (see Results).

In order to examine the olfactory knobs with the SEM, four unilaterally bulbectomized Sprague-Dawley rats were perfused as described above for the TEM analysis. The septum and ethmoturbinates were sonicated in cold cacodylate buffer for $18 \mathrm{~min}$, using a small bath sonicator set at full power (model 2200, Branson Ultrasonics, Danbury, CT). Subsequently, the tissue was postfixed in $1 \%$ osmium tetroxide in buffer for $1 \mathrm{hr}$, dehydrated through a series of graded ethanols, and dried with Peldri II (Ted Pella, Inc., Redding, CA). Finally, the tissue was sputter coated with palladium/gold using a Technics Hummer II. The olfactory epithelium was examined on a Hitachi S-520 SEM at $25 \mathrm{kV}$.

Terminology. The terminology used to describe the cell types in the olfactory epithelium has varied depending on the laboratory. As such, it is important to specify the usage in this article and its rationale. We will use the following: "basal cell," "immature neuron," and "mature neuron," which are defined as follows. We reserve the term "basal cell" for those cells that are non-neuronal or preneuronal and located near the basement membrane. The basal cell population is likely to be heterogeneous and to include cells that are actively dividing to give rise to neurons and others that express the intermediate filament protein keratin and seem to divide only rarely (Calof and Chikaraishi, 1989; Schwartz-Levey et al., 1991; Schwob, 1992). Cells are defined here as "neurons" if they are postmitotic and bear the neural cell adhesion molecule (NCAM) on their cell surface, which is an early marker for neuronal differentiation in this system (Miragall et al., 1988; Calof and Chikaraishi, 1989; Schwartz Levey et al., 1991; Schwob, 1992). We have found that NCAM labeling is contemporaneous with GAP-43 expression both in normal epithelium and in epithelium that is recovering from methyl bromide inhalation injury (Schwob and Youngentob, 1991, and unpublished observations). Therefore, GAP-43 expression also appears to be an early marker for the transition from basal cell to neuron. In addition, neurons can be classified as either "immature" or "mature" by ultrastructural and/or immunohistochemical criteria. For example, perikaryal expression of GAP-43 is characteristic of immature olfactory neurons, while OMP expression is found in mature olfactory neurons (see Results; Verhaagen el al., 1989; Meiri el al., 1991 ; Schwob, 1992). The term "globose basal cell" (Graziadei and Monti Graziadei, 1979) will not be used here, since this term as used previously may subsume both actively dividing basal cells and immature neurons that are at an early stage in the elaboration of processes. Undoubtedly, the definitive understanding of the in vivo transition from basal cell to immature neuron to mature neuron will require further investigation and the correlation of biochemically defined stages with relevant morphological and physiological parameters of maturation. Nonetheless, the immunochemical criteria listed above are adequate for the purposes of this study.

\section{Results}

Both the acute and chronic effects of bulbectomy on the olfactory epithelium and the size of the neuronal population have been described to a limited degree in rats (Le Gros Clark, 1951) and more extensively in mice and hamsters (Costanzo and Graziadei, 1983; Monti Graziadei, 1983). We find in rats as in hamsters (Costanzo and Graziadei, 1983) that the olfactory epithelium on the bulbectomized side (which we will refer to as "targetless" epithelium) remains about $24 \%$ thinner than the control epithelium on the unoperated side (data not shown), and that neuronal number is chronically reduced up to 9 months after ablation in the absence of the target, which is the longest survival period examined (data not shown). Instead of reiterating findings in rats that have already been observed in other experimental animals, we wish to focus on an evaluation of three aspects of the biology of the olfactory epithelium that lacks its target: (1) the life-span of neurons born in the absence of the bulb with reference to neuronal life-span on the unoperated side - this has been evaluated both by thymidine labeling and electron microscopic evaluation; (2) the differentiation of neurons in epithelium that lacks a target-this has been evaluated using both electron microscopic and immunochemical techniques; (3) the time course of neuronal differentiation.

\section{Life-span of neurons born in the absence of the bulb}

The life-span of neurons born in the absence of the olfactory bulb was assessed in the ipsilateral olfactory epithelium of rats 

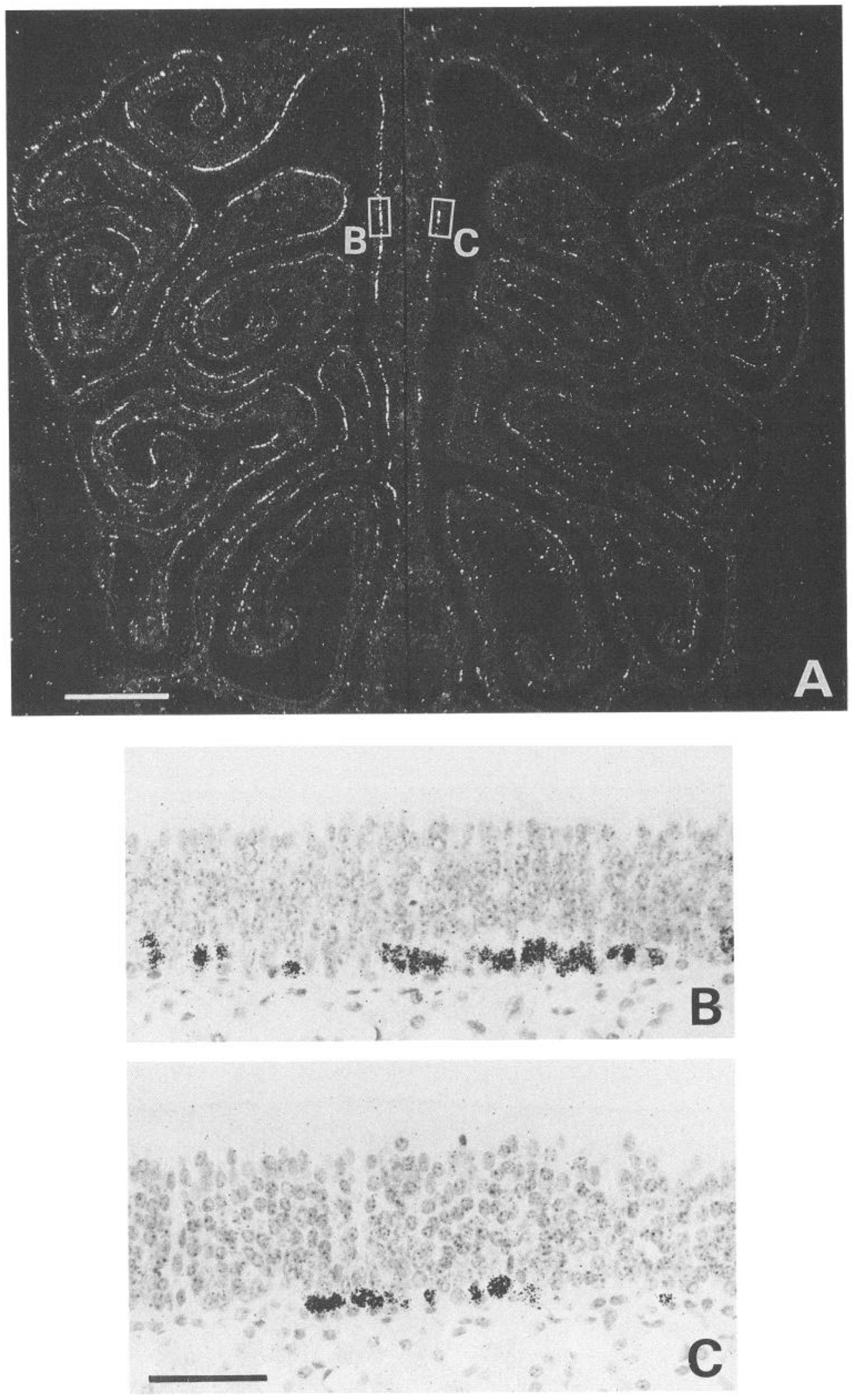

Figure 1. The rate of basal cell proliferation is increased in the olfactory epithelium at long survivals after olfactory bulbectomy. $A$, Low-power dark-field photomicrograph of a coronal section through the mid-olfactory epithelium from a rat unilaterally bulbectomized 2 months prior to injection with ${ }^{3} \mathrm{H}$-thy and then killed $2 \mathrm{hr}$ after tracer. The ablated side is on the left, and the unoperated side is on the right. $B$ and $C$, Higher-power views of the boxed areas of the septal epithelium on the ablated and control sides as indicated in $A$. Note that the increase in the number of ${ }^{3} \mathrm{H}$-thy-labeled cells is apparent in all portions of the epithelium on the ablated side. Scale bars: $A, 1 \mathrm{~mm}$; $C, 50 \mu \mathrm{m}$ for $B$ and $C$.

unilaterally bulbectomized 2 months prior to their use. The contralateral, unoperated side of the same animal served as the control. Rats were killed $2 \mathrm{hr}, 5 \mathrm{~d}$, or 2 weeks after the intravenous injection of a thymidine analog. The longer survivals were chosen to follow the cohort of labeled neurons through different time points in their life-span, which also correspond to different, definable stages of neuronal differentiation. Visual inspection of the material indicates two important differences between the epithelium on the ablated side and the control: first, neurogenesis is increased, but average neuronal life-span is 

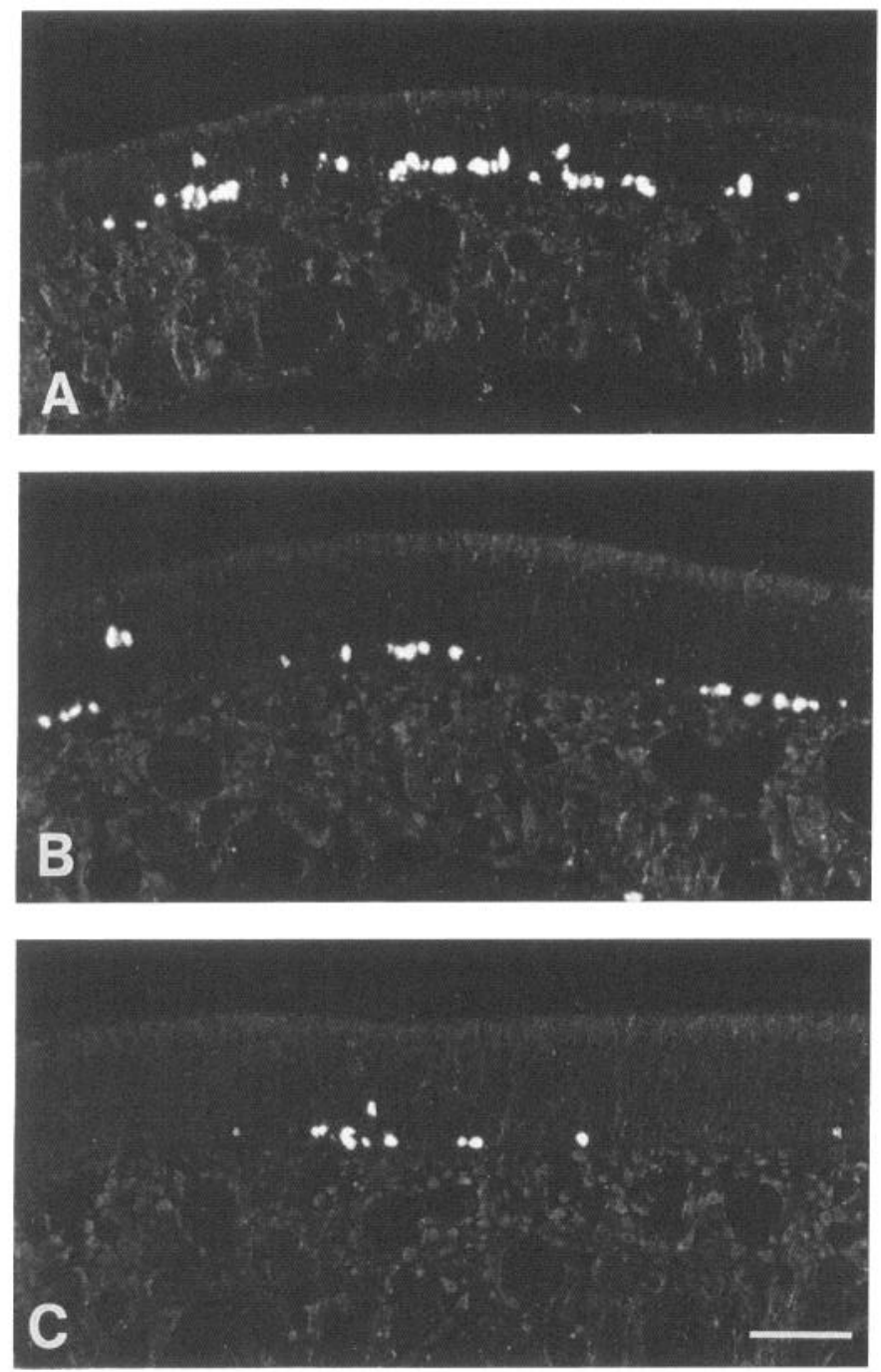

Figure 2. The rate of basal cell proliferation in the control epithelium is increased by comparison with normal. $A$, BrdU-labeled cells in epithelium lining the dorsal septum on the ablated side of a unilaterally bulbectomized rat; the ablation was performed 2 months prior to use. $B$, BrdU-labeled cells in the corresponding area of the septal epithelium on the control side of the same rat. $C$, BrdU-labeled cells in epithelium lining the dorsal septum of an age-matched normal (otherwise unmanipulated) rat. In each case, the animal was killed $2 \mathrm{hr}$ after the injection of tracer. These dark-field photomicrographs show that the rate of proliferation on the ablated side is greater than on the control side, and the rate of proliferation in the control epithelium is increased, in turn, by comparison with normal. The results illustrated here for the control and targetless epithelium are comparable to those seen with ${ }^{3} \mathrm{H}$-thy. Scale bar, $75 \mu \mathrm{m}$ for $A-C$.

shorter on the ablated side; second, during the 2 week time period after injection of tracer, neurons cycle through the width of the epithelium on the ablated side but are still concentrated in the lower part of the epithelium on the control side. These visual impressions were verified by quantitative analyses of the number and location of labeled cells at each of the three survival times as described in Materials and Methods. With respect to neuronal number, data are presented both in the form of a labeling index and as a ratio of the labeling indices on the ablated versus the unoperated side. The latter value is particularly useful for comparisons between different survival times; for example, a fall in the ratio between different survival times indicates that
Table 1. Basal cell proliferation in targetless, control, and normal epithelium

\begin{tabular}{lll} 
& $\begin{array}{l}\text { Labeling index } \\
\text { (per mm) }\end{array}$ & $\begin{array}{l}\text { Relative to } \\
\text { control }^{a}\end{array}$ \\
\hline Targetless epithelium $^{b}$ & $21.9 \pm 1.7$ & 2.3 \\
Control epithelium $^{b}$ & $9.7 \pm 0.1$ & 1.0 \\
Normal epithelium $^{c}$ & $7.5 \pm 0.7$ & 0.8
\end{tabular}

a The values were generated by dividing the labeling index for each category by the labeling index determined for the control epithelium.

"For each of three cases, labeled cells were counted on both the ablated and control sides of the same sections as described in Materials and Methods.

c For each of three cases, labeled cells were counted on both sides of the same sections as described in Materials and Methods.

labeled cells disappear relatively more rapidly from the epithelium on the bulbectomized side. The analysis of neuronal number as a function of neuronal age will be presented first, followed by a consideration of migration through the neuronal zone of the epithelium as an function of neuronal age in the presence or absence of the bulb.

As shown in animals killed $2 \mathrm{hr}$ after administration of ${ }^{3} \mathrm{H}$ thy (Fig. 1) or BrdU (Fig. 2), the rate of basal cell proliferation on the ablated side is clearly elevated by comparison with that on the unoperated side. On the ablated side, labeled basal cells are far more frequent at all rostrocaudal levels of the epithelium, and in all parts of the epithelium at a single level (Fig. 1). It is also instructive to compare the spatial pattern of labeling on the two sides. On the unoperated side, labeled basal cells tend to be clustered together (Figs. 1,2), as previously described in normal animals (Graziadei and Monti Graziadei, 1979). Likewise, on the ablated side, labeled basal cells also tend to be grouped, but the clusters are larger, both in terms of the number of labeled cells per cluster and in terms of their overall length (Figs. 1,2). The increase in the proliferation rate of basal cells in the targetless olfactory epithelium ranges between 1.6 and 3 -fold relative to the control epithelium on the unoperated side $(n=6)$. For the group of animals injected with ${ }^{3} \mathrm{H}$-thy and killed at $2 \mathrm{hr}$, this translates into a labeling index of $9.7 \pm 1.0$ labeled cells $/ \mathrm{mm}$ on the unoperated side (mean $\pm \mathrm{SD}$ ) versus $22.1 \pm$ 3.7 labeled cells $/ \mathrm{mm}$ on the ablated side, which corresponds to a 2.3-fold greater rate of basal cell proliferation on the ablated side as compared to control (see Fig. 5). In the unilaterally bulbectomized animals injected with $\operatorname{BrdU}(n=3)$, the results are comparable; the relative magnitude of basal cell proliferation on the ablated versus control side is the same in these cases as in the group labeled with ${ }^{3} \mathrm{H}$-thy (Table 1 ). It should also be noted that basal cell proliferation in the control epithelium is about $25 \%$ greater than age-matched, normal (otherwise unmanipulated) rats (Fig. 2, Table 1); there was no evidence of damage to the contralateral olfactory bulb in these unilaterally bulbectomized animals to account for the relatively greater number of labeled basal cells in the control epithelium. Scattered supporting cells are also tracer labeled in the targetless as well as control and normal epithelia, but they number less than $5 \%$ of the proliferating basal cells, and their numbers are roughly equivalent in all cases.

At $5 \mathrm{~d}$ after injection, the vast majority of the labeled cells on both sides are found superficial to the basal cell compartment in the neuronal zone of the epithelium. At this time, the number of labeled cells remains much higher on the ablated side than on the control side, and this difference is again registered 

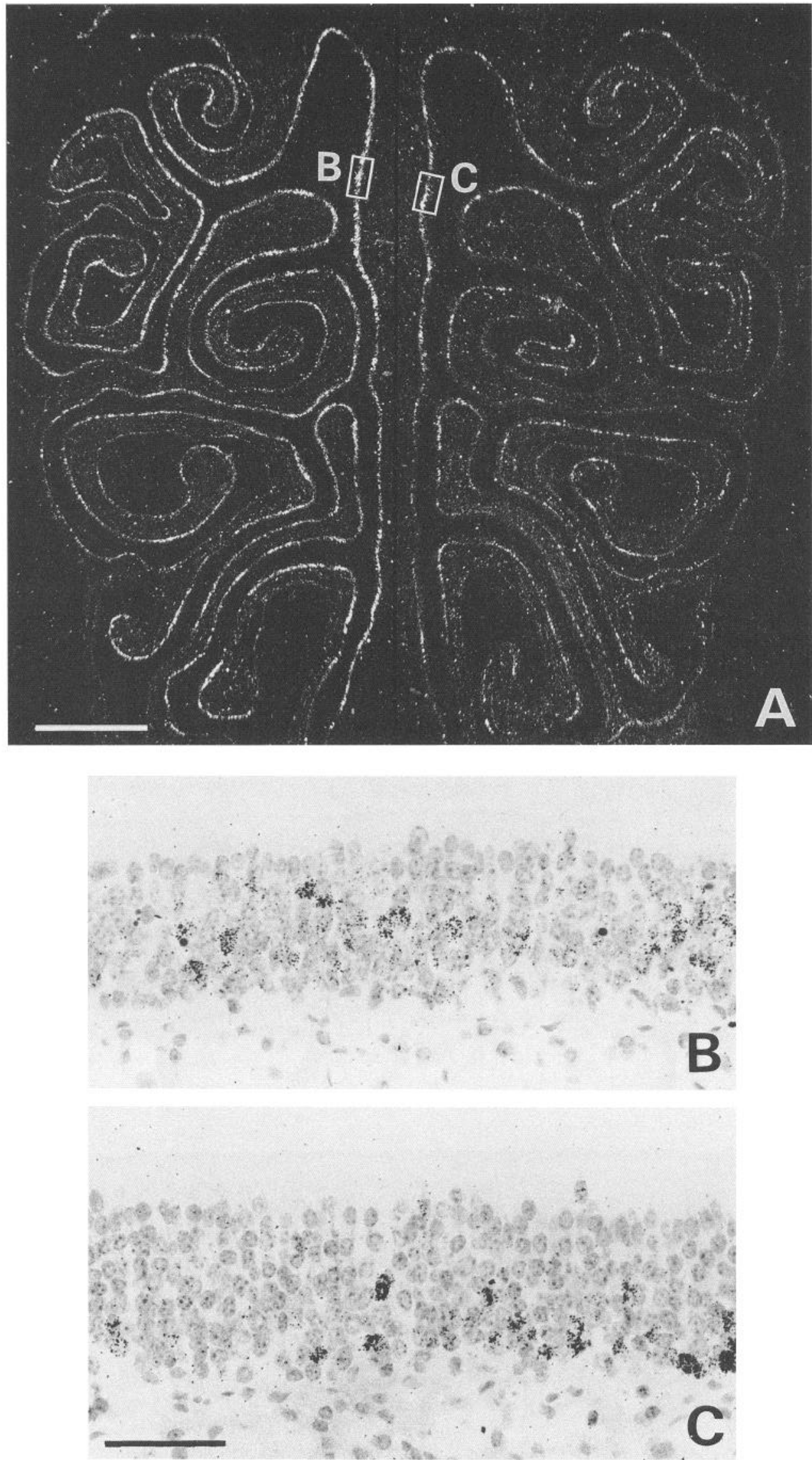

Figure 3. The increase in basal cell proliferation noted at $2 \mathrm{hr}$ after tracer persists at $5 \mathrm{~d}$ as an increase in the number of labeled neurons. $A$, Comparable location in the olfactory epithelium as illustrated in Figure 1 from a rat unilaterally bulbectomized 2 months prior to injection with ${ }^{3} \mathrm{H}$-thy and then killed $5 \mathrm{~d}$ after tracer. The ablated side is on the left. $B$ and $C$, Higher-power photomicrographs of the septal epithelium indicated by the boxed areas in $A$. Labeled neurons on the ablated side extend up to the layer of supporting cells and outnumber those on the control side. Scale bars: $A, 1 \mathrm{~mm} ; C, 50 \mu \mathrm{m}$ for $B$ and $C$. 
Figure 4. By 2 weeks, most labeled neurons have disappeared from the epithelium on the bulbectomized side, but many persist in the control epithelium. $A$, Comparable level of the olfactory epithelium as illustrated in Figures 1 and 2 from a rat unilaterally bulbectomized 2 months prior to injection with ${ }^{3} \mathrm{H}$-thy and then killed 2 weeks after tracer. The ablated side is on the left. Clusters of labeled neurons on the control side are indicated by the arrows. No such clusters are evident on the ablated side at this level in the epithelium. $B$ and $C$, Higher-power photomicrographs of the septal epithelium indicated by the boxed areas in $A$. Labeled neurons on the control side are indicated by arrowheads. No labeled neurons are seen in this area of the epithelium on the bulbectomized side. Note that grain density over the neurons in the bulbectomized epithelium is slightly higher than section background (which is also apparent in Fig. $13 A-D$ ), but is insufficient for including these neurons as labeled cells. The increased grain density most likely reflects the rapid turnover and release of ${ }^{3} \mathrm{H}$-thy and its availability at low levels for reincorporation into dividing basal cells. A similar phenomenon has been noted in regions of the embryonic retina undergoing extensive cell death (Silver, 1976). Scale bars: $A, 1 \mathrm{~mm} ; C$, $50 \mu \mathrm{m}$ for $B$ and $C$.
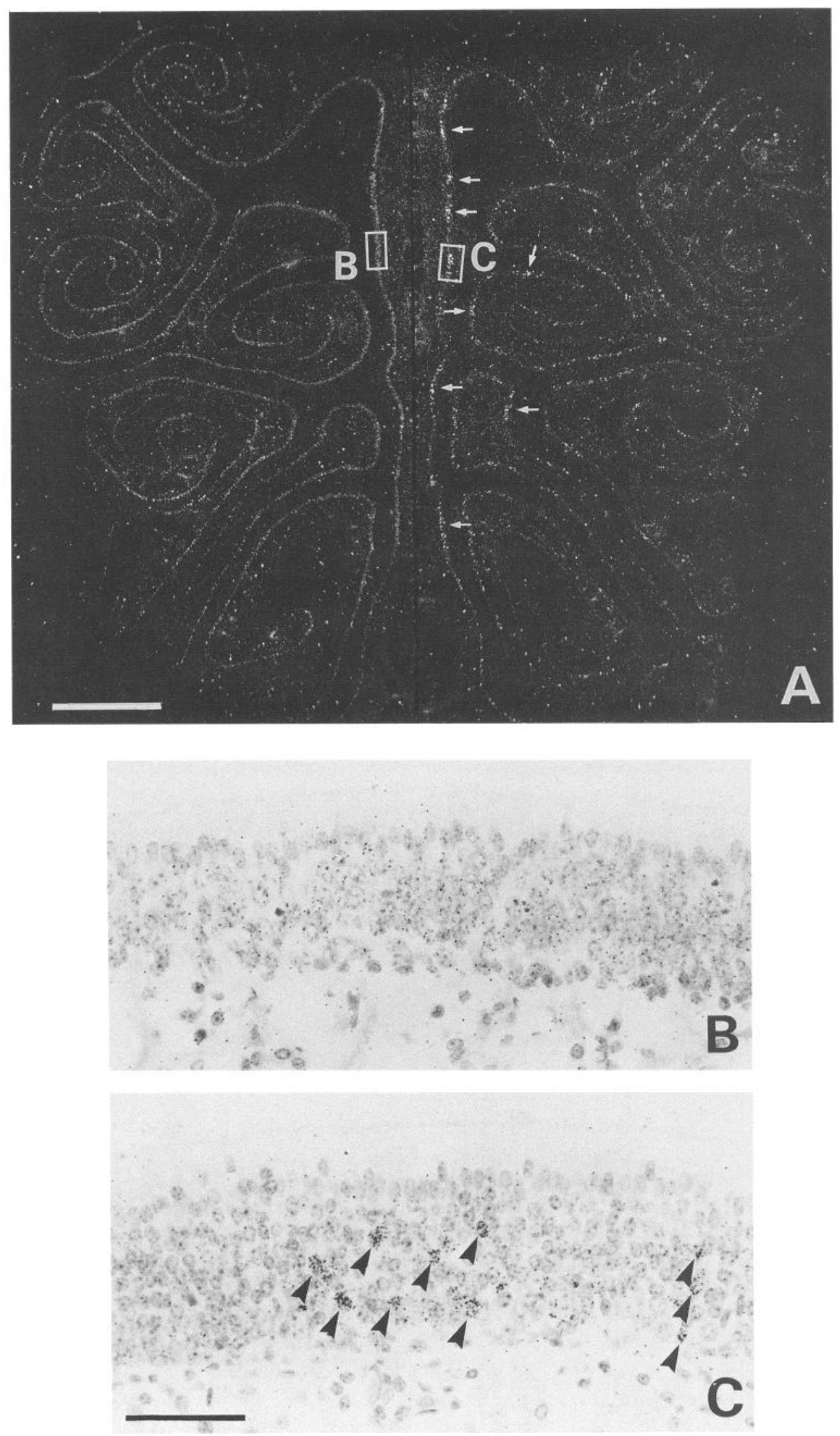

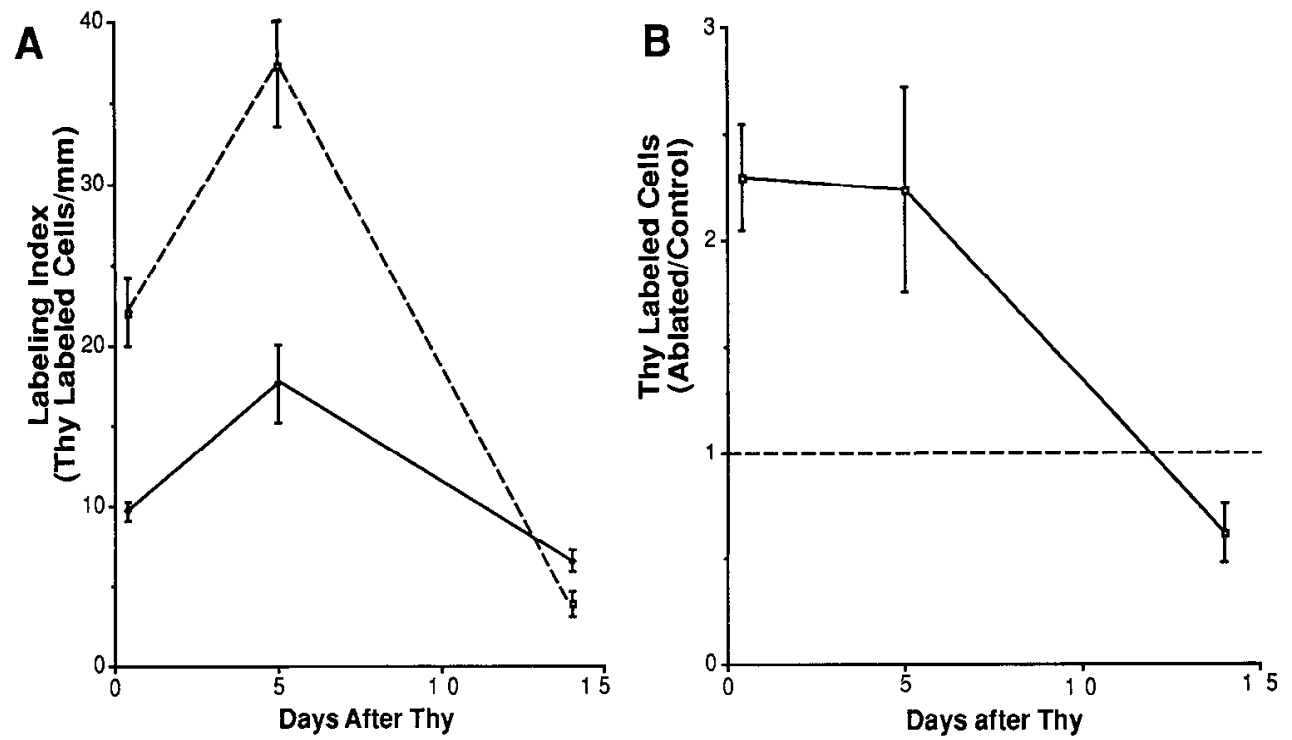

Figure 5. The rates of basal cell division and neuronal production are increased in the bulbectomized epithelium; however, neuronal death is clearly accelerated in the bulbectomized epithelium between $5 \mathrm{~d}$ and 2 weeks of neuronal age as comparcd to control. $A$, The rate of basal cell proliferation, determined at $2 \mathrm{hr}$ after tracer, and the rate of neurogenesis, determined at $5 \mathrm{~d}$ after tracer, are increased over twofold on the bulbectomized side (broken line and open boxes). However, there is substantial death of neurons on the ablated side between $5 \mathrm{~d}$ and 2 weeks of neuronal age and some loss on the control side (solid line and solid diamonds). The labeling index was generated as described in Materials and Methods. The data are expressed as the mean \pm SEM for the three animals killed at each of the three survival times after injection of the tracer: $2 \mathrm{hr}, 5 \mathrm{~d}$, and 2 weeks, which are graphed as Days after Thy. All nine animals were unilaterally bulbectomized 2 months prior to the injection of tracer. $B$, On the ablated side, a twofold increase in labeled cells is observed at both $2 \mathrm{hr}$ and $5 \mathrm{~d}$ after tracer, but the decline is relatively greater between $5 \mathrm{~d}$ and 2 weeks as shown by the fall in the ratio of the labeling indices on the two sides [Thy Labeled Cells (Ablated/Control)]. The mean + SFM ratio for each group is plotted as a function of survival time after tracer (Days after Thy). ANOVA indicates that the change in the ratio as a function of time is statistically significant $(F=8.974, p<0.02 ; \mathrm{df}=2,8)$. The broken line indicates a ratio of 1 ; that is, labeling indices are equal on the two sides. Otherwise, the conventions are the same as in $A$.

throughout the full mediolateral and anteroposterior extent of the epithelium (Fig. 3). For the group of ${ }^{3} \mathrm{H}$-thy-injected animals killed at $5 \mathrm{~d}(n=3)$, the labeling index on the ablated side ranges from 1.4 to 3.0 times greater than on the control side, and the average value on the ablated side is 2.2 -fold greater, which is similar to the difference in basal cell labeling on the two sides seen at $2 \mathrm{hr}$ after tracer (see Fig. 5). That the vast majority of these 5 -d-old cells are neurons is suggested by their position in the epithelium and the correlation of autoradiographic labeling with immunohistochemistry (described below). Therefore, not only is the difference in labcling betwecn the two sides at $5 \mathrm{~d}$ an additional demonstration that the rate of "neurogenesis" is greater in the targetless epithelium, but it may also be a somewhat more direct indication than basal cell proliferation, since it is likely that at least some of the daughter cells generated by the division of labeled basal cells reenter the mitotic cycle or arrest their differentiation and remain quiescent for some period of time (Calof and Chikaraishi, 1989; Mackay-Sim and Kittel, 1991a).

At 2 weeks after injection, autoradiographically labeled cells are very sparse in the epithelium on the ablated side, indicating that the vast majority of labeled neurons in the targetless epithelium disappear (and presumably die) by 2 weeks of neuronal age (Fig. 4). Indeed, the labeling index on the bulbectomized side has fallen $89 \%$ over the time period from $5 \mathrm{~d}$ to 2 weeks after injection of the tracer (Fig. 5). In contrast, labeled cells are still prevalent on the control side; indeed, they are now more numerous on the control side than on the ablated side in all three cases with 2 week survivals after tracer. However, it is important to note that there is some loss of labeled neurons from the control epithelium as well, corresponding to a $63 \%$ decline in the labeling index between $5 \mathrm{~d}$ and 2 weeks after tracer (Fig. 5). Nonetheless, the decline on the unoperated side during this period is smaller, both in terms of percentage and in terms of absolute changes in the labeling index, than on the ablated side; that is, more cells disappear from the targetless epithelium during this period. Indeed, the inversion of the ratio of the ablated to the control side, from 2.2 at $5 \mathrm{~d}$ after ${ }^{3} \mathrm{H}$-thy to 0.6 at 2 weeks, clearly demonstrates the more rapid decline on the ablated side (Fig. 5).

The position of labeled cells along the deep to superficial (or basal-apical) axis of the epithelium is also substantially different between the two sides at both $5 \mathrm{~d}$ and 2 weeks after injection of tracer. At $5 \mathrm{~d}$, visual examination of the ablated side indicates that the labeled neurons are distributed through most of the width of the neuronal compartment of the epithelium, since they can be found from the basal cell layer up to the level of the supporting cells. In contrast, the labeled neurons on the control side are largely confined to the depths of the epithelium in all three cases. This visual impression is confirmed by plotting neuronal position, either in terms of absolute distance from the basal lamina (not shown) or as a proportion of the distance between the basal lamina and the supporting cell layer (Fig. 6A). Although there is some overlap in the distribution along the apical-basal axis on the two sides, the average position of the labeled cells is clearly more superficial on the ablated side as compared with the control epithelium.

At 2 weeks, the labeled cells on both sides are more superficial in the epithelium, on average, than at $5 \mathrm{~d}$. However, the neurons are still differentially distributed on the two sides; labeled neurons on the ablated side are concentrated at the apical limit of the neuronal zone just deep to the supporting cell layer, while 

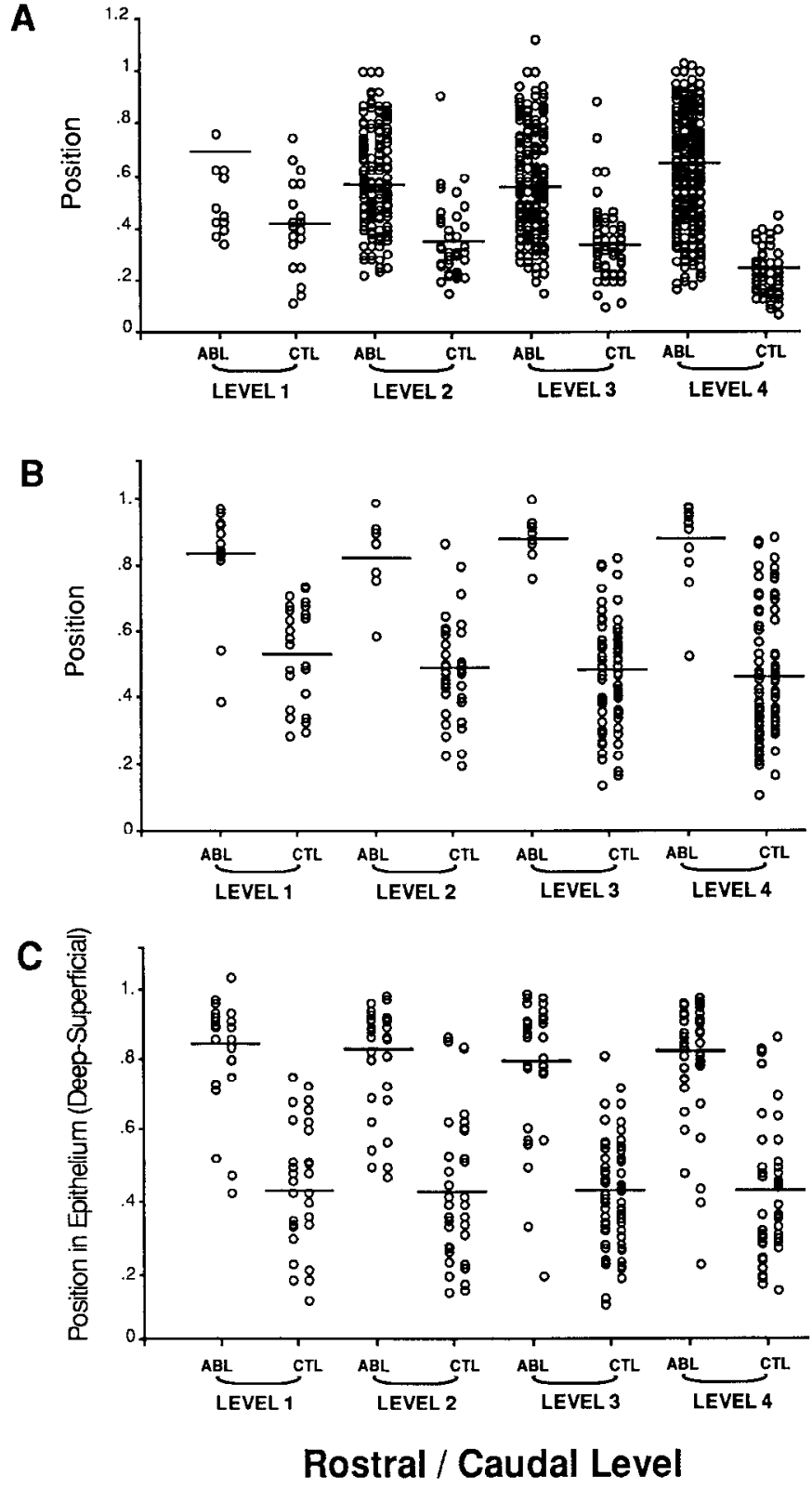

Figure 6. Labeled neurons are found more superficially in the epithelium on the bulbectomized side at both $5 \mathrm{~d}$ and 2 weeks of neuronal age. $A$, By $5 \mathrm{~d}$ after injection of ${ }^{3} \mathrm{H}$-thy, labeled neurons on the ablated side have migrated apically to fill the width of the neuronal zone of the epithelium. On the control side, the 5-d-old neurons are situated more deeply on average. Distance from the basal lamina (i.e., height in the epithelium) was measured for each labeled neuron along the septum at four different levels in the epithelium on both the ablated $(A B L)$ and control (CTL) sides; LEVEL 1 is located far rostral in the epithelium where the endo- and ectoturbinates have almost completely disappeared, while $L E V E L 4$ is caudal in the epithelium, located just anterior to the olfactory bulb. $L E V E L 2$ and $L E V E L 3$ are located equidistant between these two endpoints. The height of each neuron is plotted those on the control side tend to be located in the decper half of the neuronal zone for the most part (Fig. $6 B, C$ ). The results are the same, independent of the number of labeled cells remaining in the targetless epithelium at this time. For example, in the case illustrated in Figure $6 B$ (JS290), very few labeled neurons are evident on the ablated side, while in the case illustrated in Figure 6C (JS292), there are substantially more labeled neurons (although still fewer than on the control side). Nonetheless, neuronal position on the ablated side, averaged over all of the levels, is roughly the same in the two cases $(0.84$ vs. 0.81 for JS290 vs. JS292, respectively), despite the difference in number.

\section{Olfactory neurons are morphologically immature in the targetless epithelium}

The absence of the bulb apparently has consequences for the composition of the population of olfactory ncurons with respect to both health and maturity, when these features are assessed morphologically. The olfactory epithelium and lamina propria from both sides of the nose of animals unilaterally bulbectomized 1 month or more prior to death were examined with TEM and SEM. Our observations on the control epithelium, harvested from the unoperated side of a unilaterally bulbectomized rat, are quite similar to our own examination of the normal rat olfactory mucosa (not shown) as well as previously published descriptions in the mouse (Frisch, 1967; Graziadei and Monti Graziadei, 1979). At low power, the epithelium on the unoperated side is divisible into three cellular zones (Fig. $7 \mathrm{~B}$ ). Adjacent to the basal lamina is the zone containing basal cells and immature neurons. The next more superficial is the zone containing the perikarya of presumptively more mature olfactory neurons, which we classify as such because their nuclear chromatin is slightly more condensed and their cytoplasm, including that in the olfactory knob, is significantly darker. These criteria are substantiated by our further electron microscopic evidence on ciliagenesis and by the immunohistochemical analysis described below. Finally, the nuclei and perikarya of the sustentacular cells occupy the most superficial zone. Microvillar cells (Moran et al., 1982; Rowley et al., 1989) are also seen superficially; their apical processes contain mitochondria in abundance and lack

relative to the width of the epithelium to the middle of the layer of supporting cells [Position in Epithelium (Deep-Superficial)]. The average values are indicated by the horizontal lines. Values greater than 1 indicate that the neurons were located superficial to the supporting cell layer. $B$ and $C$, By 2 weeks after tracer injection, the labeled neurons have migrated farther toward the apex of the epithelium on both sides. Two cases are illustrated that differ according to the number of labeled neurons that remain at 2 weeks on the ablated side. In both, most of the neurons on the ablated side are situated at the upper limit of the neuronal zone whether there are only a few 2 -week-old neurons remaining $(B)$ or whether there are substantially more $(C)$. The levels that were analyzed and the conventions are the same as in $(A)$.

Figure 7. At long survivals after bulbectomy, the epithelium is populated by immature neurons. The low-power electron micrographs of olfactory epithelium on the ablated $(A)$ and control $(B)$ sides are taken from matched locations on the nasal septum from a rat unilaterally bulbectomized 4 weeks prior to death. On the control side, note the cytoplasmic darkening of the mature neurons located just below the supporting cells ( $s$ ). In contrast, some neurons on the ablated side show a slight increase in cytoplasmic density over the basal cells, but fully darkened, that is, mature, neurons are absent. The bulbectomized epithelium also differs by the presence of cell fragments $(f)$ and pyknotic neurons with lucent cytoplasm $(p)$. Microvillar cells $(m)$ are prominent in the bulbectomized epithelium. The double arrowheads indicate the basal lamina. The boxed areas in $A$ and $B$ are shown at higher power in Figs. $8 A$ and $8 B$, respectively. Scale bar, $20 \mu \mathrm{m}$ for $A$ and $B$. 

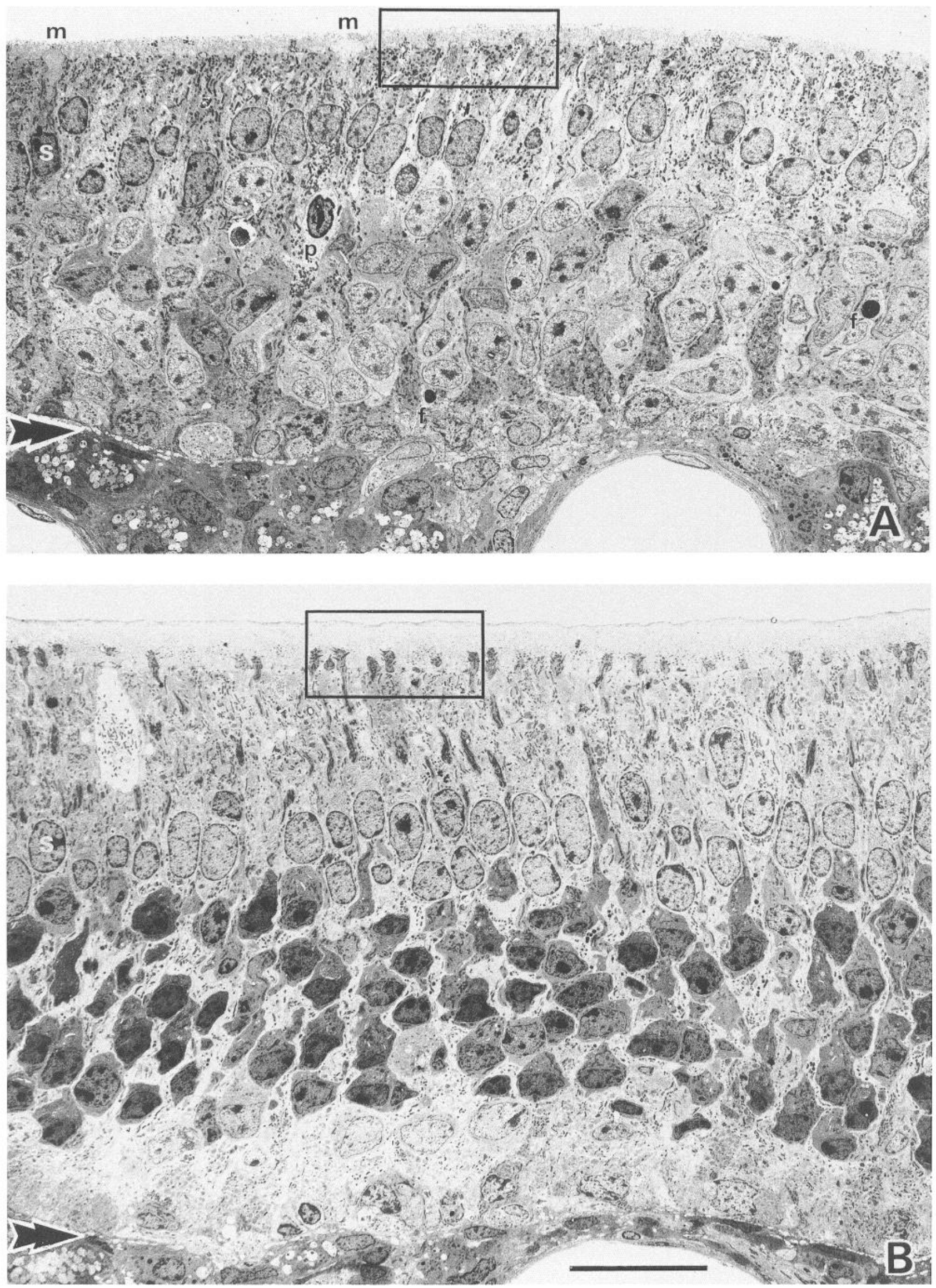

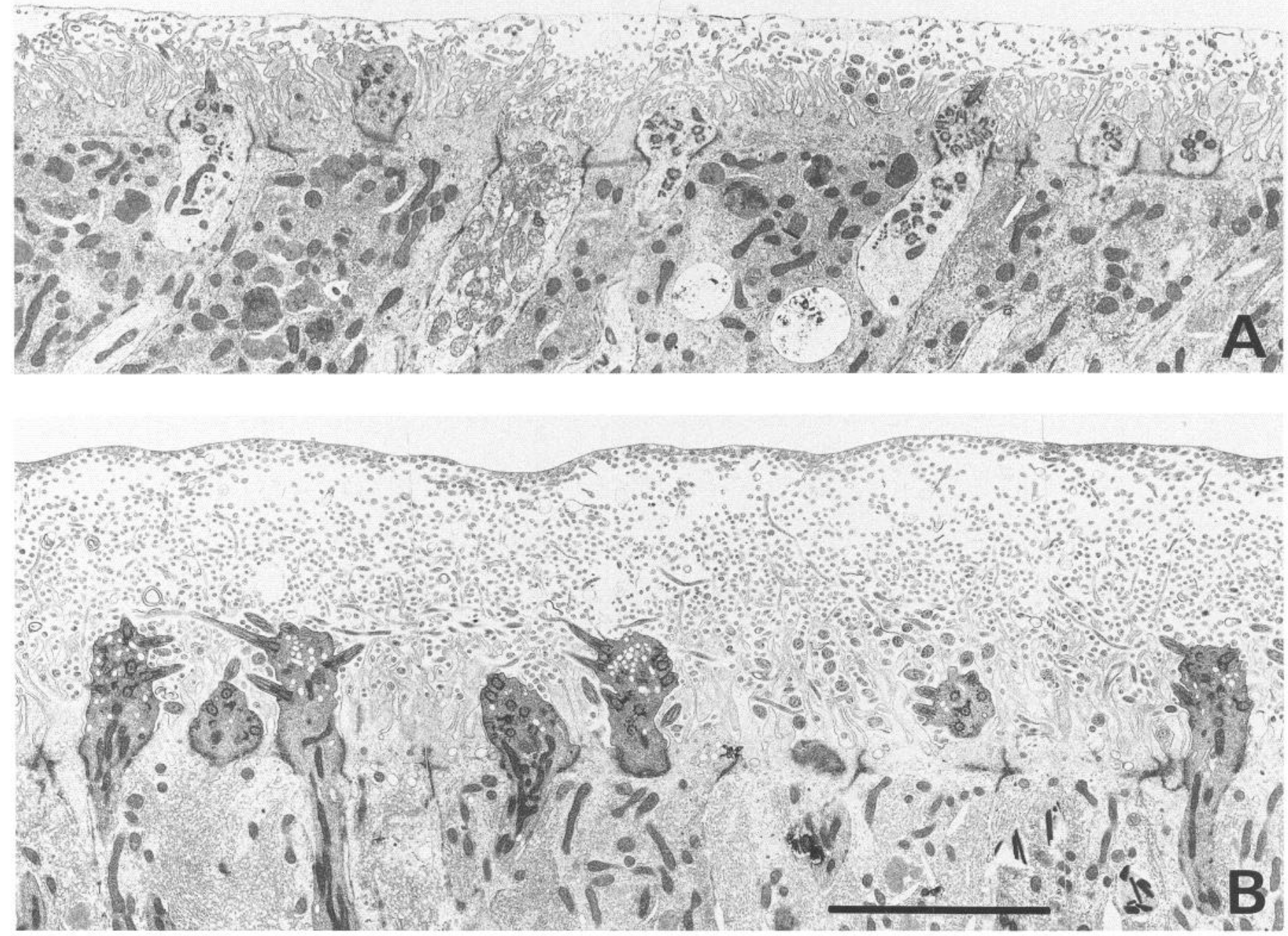

Figure 8. In the bulbectomized epithelium neurons are immature and fail to make cilia. $A$, On the ablated side, note that most olfactory knobs do not bear cilia and are located at or just above the free surface and terminal web of the supporting cells [terminology of Frisch (1967)]; basal bodies are concentrated in the center of the knobs. In addition, there is no dense mat of fine cilia between the microvillous surface of the supporting cells and the air-mucus interface, which is the fine dense line. $B$, In contrast, on the control side knobs contain darker cytoplasm, extend further above the free surface of the supporting cells, and bear many cilia; the basal bodies sit at the rim of the knob where they give rise to cilia. The mat of fine cilia between the knobs and the air-mucus interface is both dense and thick. Note the concentration of cilia at this interface. Scale bar, 5 $\mu \mathrm{m}$ for $A$ and $B$.

endoplasmic reticulum, which allows them to be differentiated from supporting cells.

With the TEM, three differences between the unoperated side and the bulbectomized side are apparent on comparison of closely matched areas of the olfactory mucosa lining the nasal septum or the endoturbinates: first, on the ablated side mature olfactory neurons are largely absent; second, olfactory knobs at the surface of the targetless epithelium lack cilia; and third, many of the axons in the fila olfactoria on the ablated side appear to be degenerating.

With regard to the first of these differences, the epithelium on the bulbectomized side is markedly thinner than control (Fig. $7 A$ ). Mature olfactory neurons, defined using the criterion of cytoplasmic darkening, are very infrequent, and when found tend to be the most superficial neurons in the epithelium. Hence, the zone normally occupied by mature olfactory neurons is thin and ill defined, or absent. However, the numbers of basal cells and immature neurons are increased on the ablated side as compared to control, and the zone of the epithelium that they occupy is correspondingly thicker. Microvillar cells are present in the superficial part of the epithelium (Fig. $7 A$ ). Indeed, they may be slightly more frequent on the ablated as compared to the control side.

With regard to the elaboration of cilia, the apical surface of the epithelium is clearly different between bulbectomized and control sides (Fig. 8). On the control side, most of the olfactory knobs have a characteristically mature morphology (Reese, 1965; Menco and Farbman, 1985): the basal bodies are arranged as a rim around the outside of the knob, the knobs have elaborated large cilia that can be seen to project for substantial distances immediately above the level of the supporting cell microvilli, and their cytoplasm is also darker than that of supporting cells or microvillar cells in the vicinity. Moreover, a dense mat of thinner cilia overlies the knobs and extends to the air-mucus 
layer interface, which can be recognized as a thin accumulation of electron-dense material (Fig. $8 B$ ). In contrast, on the bulbectomized side, there are fewer knobs and most of them have a characteristically immature appearance: the basal bodies tend to be clustered in the middle of the knob, most of them lack cilia, and the cytoplasm of the knobs is lighter than on the control side, judging by reference to the surrounding cells. Most strikingly, the mat of fine cilia that fills the mucus layer on the control side is absent on the bulbectomized side. The difference between ablated and control cannot be explained by an artifactual disruption of the mucus layer of the epithelium on the bulectomized side, since the line of electron-dense material that delimits its interface with the air has been preserved (Fig. 8A).

This visual impression can be documented by counts of knobs at the surface of the epithelium. For a particular knob, the attachment of two or more cilia in the plane of the section was used as the criterion that a knob is "mature." On the bulbectomized side, there are $78 \pm 5 \mathrm{knobs} / \mathrm{mm}$, which corresponds to a decrease of $52 \%$ compared to $150.5 \pm 18 \mathrm{knobs} / \mathrm{mm}$ on the control side. Of the knobs on the bulbectomized side, only $12.5 \pm 5.5 \%$ are multiciliated (i.e., two or more cilia evident in the plane of the section) as compared to $67.5 \pm 3 \%$ that are multiciliated on the control side; the difference between the two sides is statistically significant both in terms of absolute numbers of multiciliated knobs and when expressed as a percentage of the total number of $\operatorname{knobs}(t=17.22$ and $t=14.85$, respectively; in each case, $p<0.01$ and $n=3$ ).

SEM can be used as an alternative means of viewing knobs and the elaboration of cilia after the mucus layer has been removed from the surface of the fixed epithelium by brief sonication (Fig. 9). This technique also confirms that knobs are fewer on the bulbectomized side, and that most of them either lack cilia or have only one or two stubs; a few knobs on the ablated side appear to bear a normal number of cilia. They may correspond to the small percentage of multiciliated knobs that was evident in the targetless epithelium with TEM. In contrast, the vast majority of the knobs on the control side have multiple cilia. It should be noted that visualization of the knobs also requires that the ciliary mat be stripped from the epithelial surface by fracturing cilia near the knob. Therefore, differences in the length of cilia elaborated (rather than number) cannot be assessed with this method of tissue preparation. Any such differences would also contribute to the marked reduction in the thickness and density of the ciliary mat on the bulbectomized side.

The third difference noted between the targetless and control mucosa pertains to the morphology of olfactory axons in the fila olfactoria (Fig. 10). On the control side, the vast majority of olfactory axons are rather uniform in appearance and are somewhat darker than the investing loops of Schwann cell cytoplasm; their diameters fall within a narrow range around $0.1-$ $0.2 \mu \mathrm{m}$. In contrast, on the bulbectomized side, many of the axons are undergoing an electron-lucent form of degeneration. Characteristically, the degenerating axons are swollen and the axoplasm is pale by comparison with axons of normal diameter. In addition, many of the swollen profiles contain phagosomes, and/or their surface membranes are fragmented.

Comment. The dilated, fragmented axons found in the fila olfactoria at long survivals after bulbectomy resemble degenerating axons observed distal to the site of experimental transection of the olfactory nerve, for example in the central stump of the olfactory nerve in the frog (Graziadei, 1974) and in the
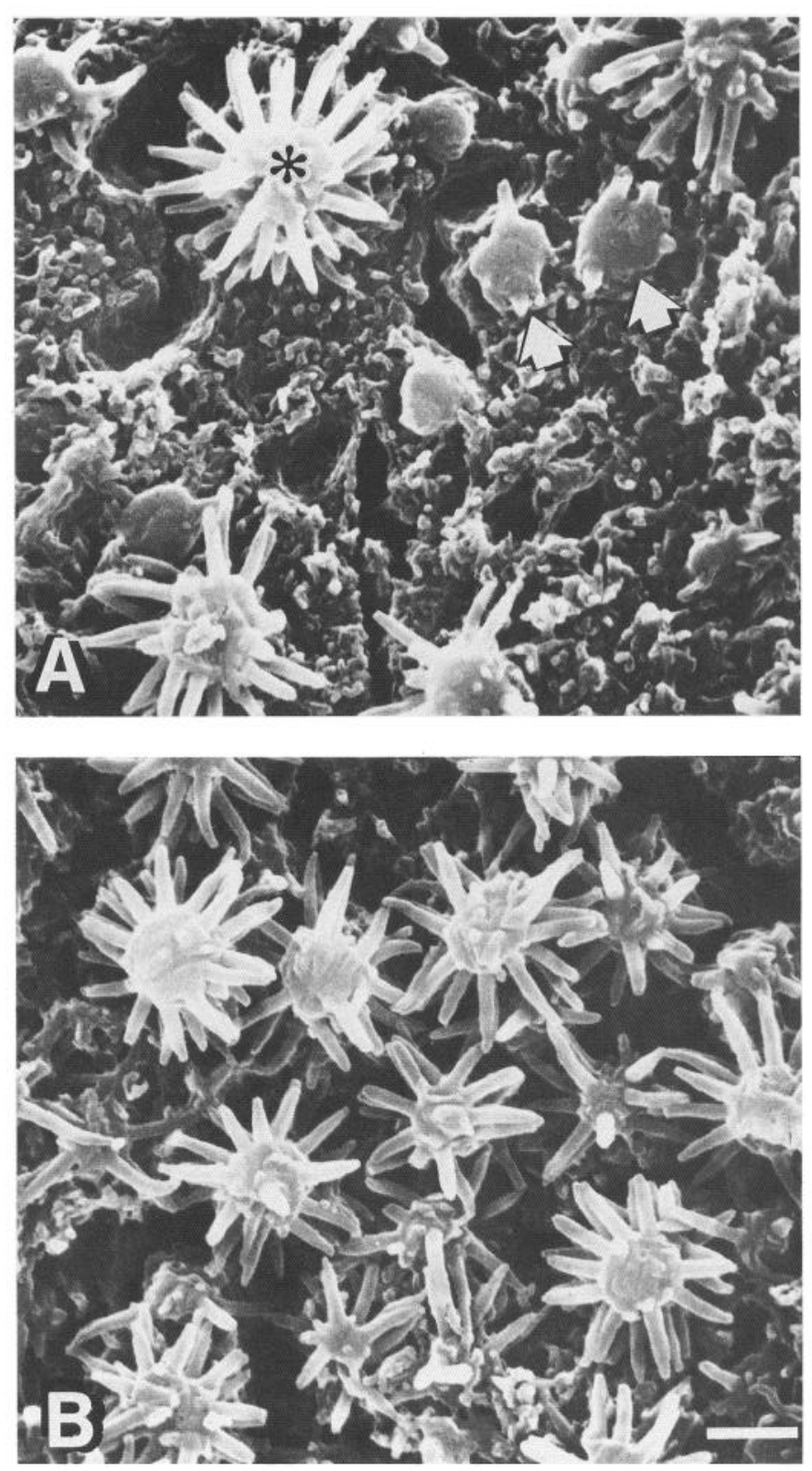

Figure 9. Although most knobs seen in the bulbectomized epithelium lack cilia, some do have a nearly full complement of cilia. $A$ and $B$, Scanning electron micrographs of the surface of the epithelium at matched locations on the nasal septum on the ablated and control sides, respectively. The arrowheads indicate examples of knobs that elaborate only a few cilia, and would correspond to ones illustrated in Fig. 8A. Others in the bulbectomized epithelium more closely resemble the knobs on the control side (asterisk), and presumably correspond to more mature neurons. Scale bar, $1 \mu \mathrm{m}$ for $A$ and $B$.

mammalian olfactory nerve layer (Berger, 1971; Graziadei and Monti Graziadei, 1980). Likewise, we have observed similar axonal changes in the lamina propria of the mucosa at 4 or $6 \mathrm{~d}$ after bulb ablation, when pale, swollen, and fragmented olfactory axons are abundant in the fila olfactoria on the ablated side (not shown); at this time retrograde neuronal degeneration is massive and ongoing (also see Monti Graziadei and Graziadei, 1979). Furthermore, axons in other parts of the nervous system, particularly early in development, also undergo an electronlucent type of degeneration similar to that which we describe here (Cook et al., 1974; Westrum, 1980). Less frequently, swol- 

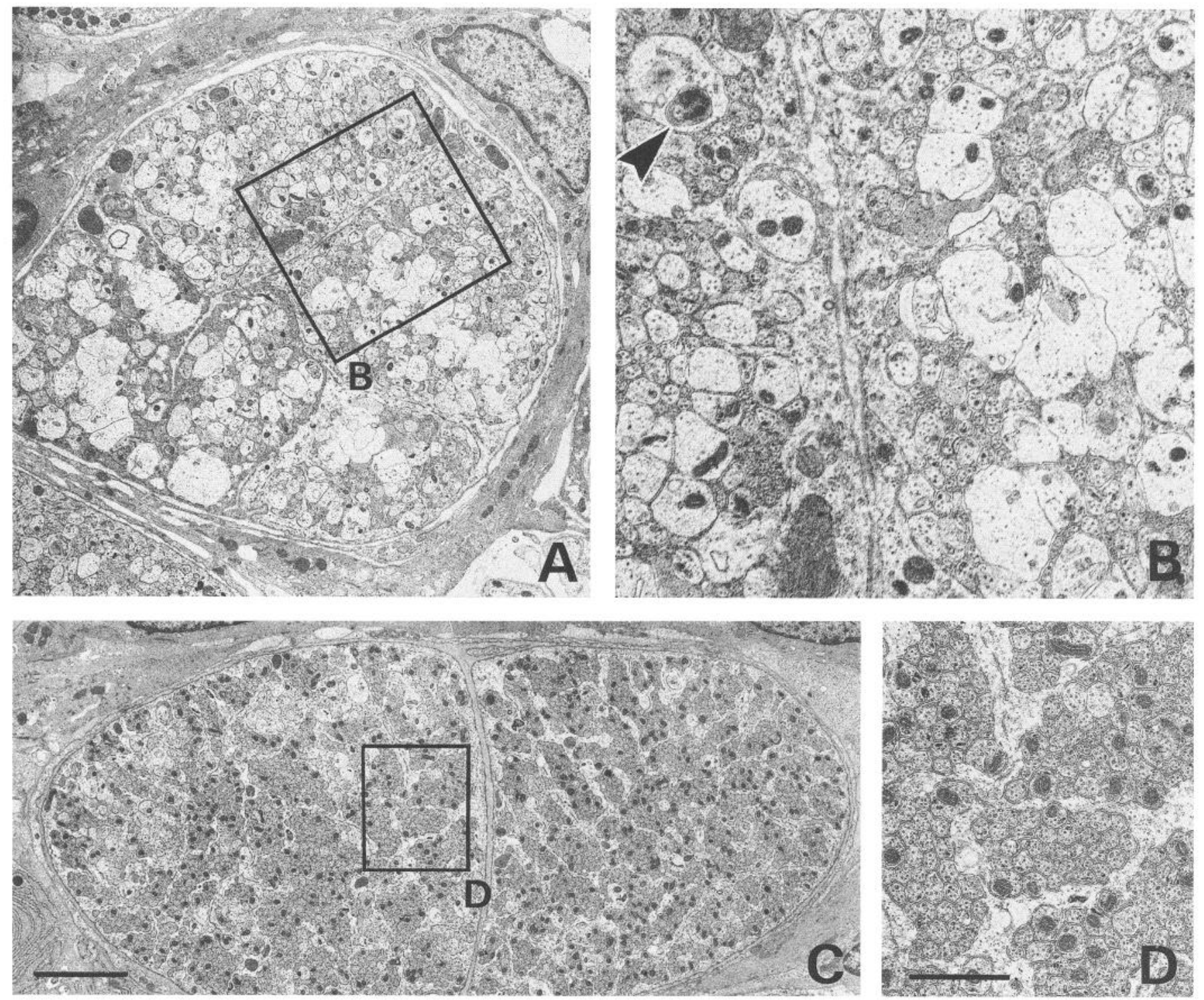

Figure 10. $A$ and $B$, Electron-lucent axonal degeneration is prominent in the fila olfactoria on the ablated side, indicating that neuronal death is accelerated for neurons born in the bulbectomized epithelium. Most axons are swollen and contain pale cytoplasm; in many cases, the axonal membrane is broken and fragmented. The boxed area is shown at higher power in $B$. The arrowhead indicates an intraxonal phagosome, which is similar to those observed distal to olfactory nerve transection (Berger, 1971). $C$ and $D$, In contrast, axons in the fila olfactoria on the control side are small and regular in diameter and normal in appearance. The boxed area is shown at higher power in $D$. Both sets of micrographs are taken from the lamina propria deep to epithelium illustrated in Figure 7. Scale bars: $C, 2.5 \mu \mathrm{m}$ (also applies to $A$ ); $D, 1 \mu \mathrm{m}$ (also applies to $B$ ).

len, fragmented axons are observed in the fila olfactoria on the control side, which is an indication that neuronal death is also ongoing on the unoperated side, and would be expected from our demonstration that thymidine-labeled neurons disappear from the control mucosa. On both sides, some of the swollen, pale, and unfragmented profiles may be growth cones. However, we have yet to see the collections of endoplasmic reticulum, dense-core vesicles, or other organelles that characterize axonal growth cones described in other neuronal systems in vivo (Del Cerro and Snider, 1968; Skoff and Hamburger, 1974; Fox et al., 1976). Likewise, some of these swollen axons may be immature rather than degenerating, since olfactory axons harvested at early stages in the embryonic development of the olfactory nerve are sometimes dilated for a portion of their length proximal to the growing tip (Cuschieri and Bannister, 1975). However, the fragmentation, the presence of phagosomes, and the degree of lu- cency of most of the dilated profiles on the bulbectomized side suggest that most of the swollen axons are truly degenerating.

\section{Expression of biochemical markers of neuronal differentiation after bulbectomy}

In addition to the effects on neuronal life-span and morphological differentiation, we have observed altered patterns of expression of certain biochemical markers associated with different phases in the life cycle of olfactory neurons. We have used the expression of GAP-43 in neuronal somata as a marker for immature olfactory neurons and the expression of OMP as a marker for more mature neurons, in keeping with previous work (Monti Graziadei, 1983; Menco, 1989; Verhaagen et al., 1989; Meiri et al., 1991; Schwob, 1992). In normal epithelium, the expression of these proteins is roughly reciprocal, since OMPcontaining olfactory neurons predominate in the olfactory ep- 

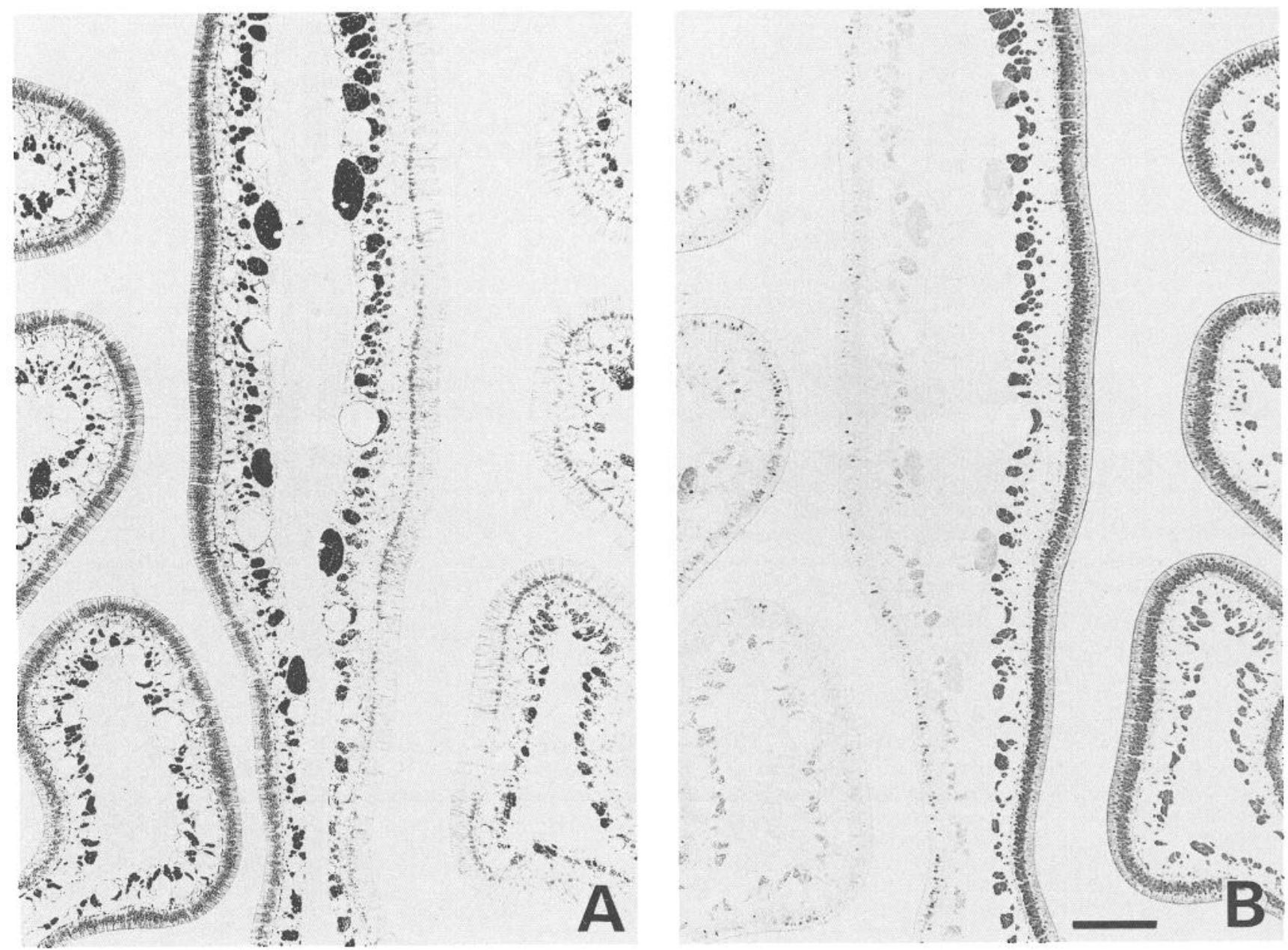

Figure 11. Immunochemically defined immature neurons predominate in the targetless epithelium. $A$ and $B$, Adjacent coronal sections of the septal and endoturbinal parts of the olfactory epithelium from a rat unilaterally bulbectomized 2 months prior to death stained with antisera to GAP-43 and OMP, respectively. Dorsal is above, the ablated side is to the left, and the control side is to the right in both micrographs. Most neurons on the ablated side contain GAP-43 but lack OMP and the reverse is true on the control side. Scale bar, $250 \mu \mathrm{m}$ for $A$ and $B$.

ithelium of normal, sexually mature rodents, while olfactory neurons containing GAP-43 in their cell bodies are both confined to the depths of the epithelium just superficial to the basal cells and more limited in number (Verhaagen et al., 1989; Meiri et al., 1991).

When the relative expression of OMP and GAP-43 was assessed on adjacent sections of the olfactory mucosa from rats 1-9 months after unilateral bulb ablation (the longest survival examined), we find that the number of neurons expressing OMP is markedly less on the ablated side (Fig. 11). Conversely, the number of olfactory neurons containing GAP-43 in their cell bodies is substantially greater on the bulbectomized side (Fig. 11). On both control and ablated sides, the populations of immature and mature neurons are roughly complementary to each other based on the assessment of adjacent sections, with OMP neurons situated more superficially. Likewise, axonal labeling was assessed by examining the fila olfactoria in the lamina propria. On the ablated side, there is much less OMP labeling of the fila olfactoria as well as much heavier GAP-43 staining relative to the control; both results presumably reflect the corresponding differences in the neuronal population. Similar findings were obtained with any of three monoclonal antibodies that recognize both phosphorylated and nonphosphorylated forms of GAP-43 (Meiri et al., 1991) or with a polyclonal antiserum raised against a GAP-43/ $\beta$-galactosidase fusion protein (Curtis et al., 1991).

The apparent complementarity of expression of GAP-43 and OMP was directly assessed with double immunofluorescent labeling (Fig. 12). In general, the two proteins are indeed reciprocally expressed on the ablated or control sides (Fig. 12) and likewise in normal epithelium (not shown), as was suggested by the analysis of adjacent sections; that is, neurons are labeled either with anti-GAP-43 or anti-OMP but not both. Nonetheless, in all three of these conditions, some neurons contain both OMP and GAP-43 and they are somewhat more frequent in the targetless epithelium. The doubly labeled neurons tend to be less heavily labeled by one or the other of the two markers. For example, neurons that are intensely stained with anti-GAP-43 may rarely contain OMP, but the anti-OMP staining tends to be relatively weaker, and by inference the level of OMP expression is lower, than is characteristic of fully mature neurons located more superficially in the epithelium. The converse result, that is, cells weakly stained with anti-GAP-43 and intensely stained with anti-OMP, is also observed. It is worth emphasizing that the relationship between maturation and the deep-superficial axis of the epithelium is maintained in the targetless ep- 

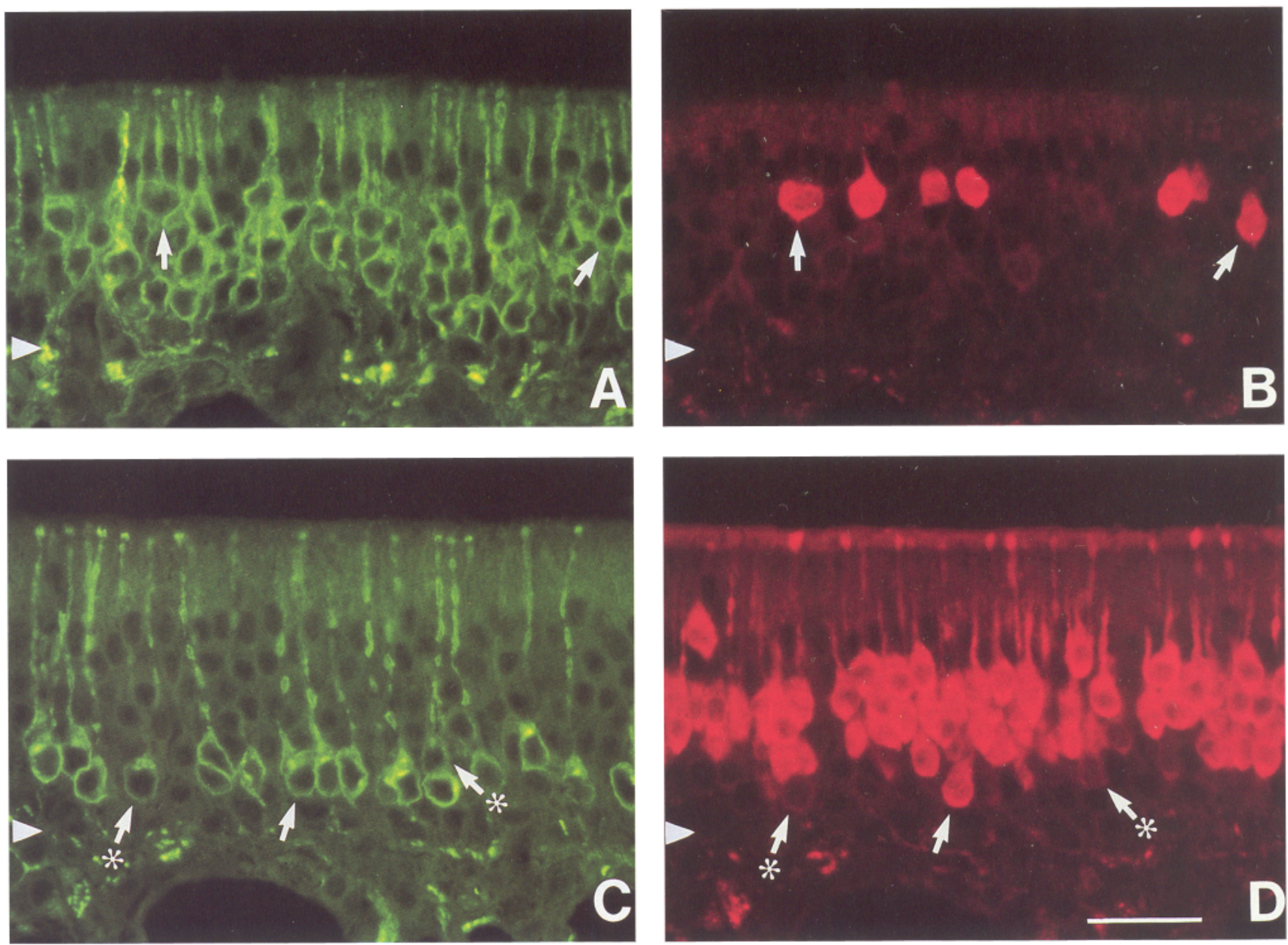

Figure 12. The expression of GAP-43 and OMP is largely reciprocal in either the ablated or control epithelium; however, occasional doublelabeled neurons are present on both sides. $A$ and $B$, Septal epithelium on the ablated side. $C$ and $D$, Matching location on the control side of the same section. $A$ and $C$, Staining with antiserum to GAP-43 (visualized with fluoresceinated avidin as described in Materials and Methods). $B$ and $D$, Photographs of the identical fields as $A$ and $C$, respectively, demonstrating the staining with antiserum to OMP (visualized with Texas redconjugated secondary). The arrows indicate double labeled cells. The ones with the asterisks are only lightly labeled with the antiserum to OMP. Scale bar, $30 \mu \mathrm{m}$ for $A-D$.

ithelium; those neurons that contain OMP alone on the ablated side tend to be the most superficially placed neurons in the epithelium (Fig. 12).

The immunohistochemical results correlate well with our demonstration that most olfactory neurons in the targetless epithelium are morphologically immature at the electron microscopic level (as described in the preceding section of the Results) and are entirely consistent with previous findings that immunochemically defined immature neurons predominate in the epithelium as a consequence of bulbectomy (Monti Graziadei, 1983; Verhaagen et al., 1990). However, since neurogenesis is accelerated and neuronal life-span is apparently shorter on the ablated side (see above), the relative increase in the numbers of immature neurons on the ablated side by itself cannot be taken as a clear indication that neuronal differentiation has been affected in the absence of the bulb. Indeed, either the relative increase in immature neurons on the ablated side would have to exceed the relative increase in neurogenesis, or the timing of the transition from immature (i.e., GAP-43-containing) to mature (i.e., OMP-expressing) neurons would have to be delayed, in order to conclude that differentiation is affected. Accordingly, we have combined immunohistochemistry with ${ }^{3} \mathrm{H}$-thy auto- radiography to examine when OMP and GAP-43 are expressed during the life span of neurons born in the absence (bulbectomized side) or presence (unoperated side) of their target. Furthermore, we have directly compared the rate of basal cell proliferation to the numbers of GAP-43-containing neurons in bulbectomized versus control epithelium to determine whether the proportion of immature neurons to proliferating basal cells is similar on the two sides. Finally, we have counted the number of neurons that contain both GAP-43 and OMP in order to assay whether the switch from GAP-43 to OMP expression is prolonged in the absence of the target, since it is likely that these doubly labeled neurons correspond to this transition phase in the differentiation of olfactory neurons. Each of these results will be described in turn.

The timing of the transition from GAP-43 labeling to OMP expression in the neuronal soma is similar on the bulbectomized and unoperated side. At $2 \mathrm{hr}$ after tracer, autoradiographically labeled cells are not stained by either antibody; rather, they are found deep to the band of immature, GAP-43-positive cells (data not shown). At $5 \mathrm{~d}$ after injection, over $90 \%$ of the autoradiographically labeled neurons on either side contain GAP43 , although they are more numerous in the targetless epithe- 

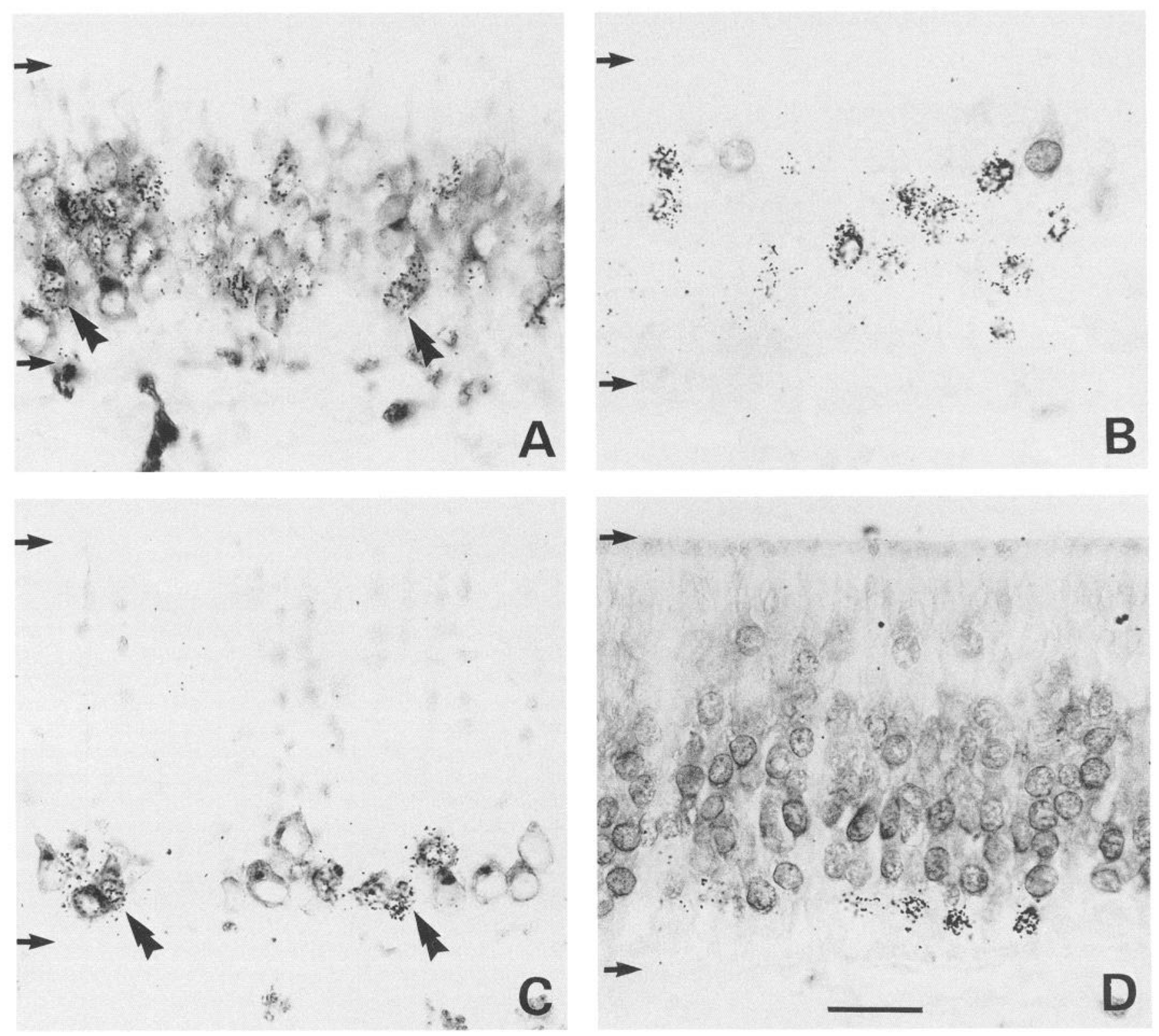

Figure 13. Five-day-old neurons are predominantly immature by immunohistochemical criteria in both the bulbectomized and control epithelium. All four micrographs are taken from the same experimental animal unilaterally bulbectomized 2 months prior to injection of ${ }^{3} \mathrm{H}$-thy and killed 5 d after tracer. $A$ and $B$, Olfactory epithelium from the septum on the ablated side. $C$ and $D$, Olfactory epithelium from the similar location on the control side. $A$ and $C$, Stained with antiserum to GAP-43. $B$ and $D$, Stained with antiserum to OMP. Examples of cells that are autoradiographically labeled and also stained with the antiserum to GAP-43 are indicated by the double arrowheads. None of the anti-OMP-stained cells are autoradiographically labeled. The arrows indicate the basal lamina and the apical surface of the epithelium. In each photomicrograph, the apical surface of the epithelium is $u p$. Scale bar, $20 \mu \mathrm{m}$ for $A-D$.

lium, as a consequence of the higher rate of neurogenesis on that side (Fig. 13A,C; Table 2). At this time, ${ }^{3} \mathrm{H}$-thy/OMP doubly labeled neurons are virtually nonexistent (Fig. 13B,D). Indeed, the small proportion of the ${ }^{3} \mathrm{H}$-thy-labeled cells that do not also contain GAP-43 seem to be either basal cells, since they are found adjacent to the basal lamina, or can be identified as supporting cells on the basis of nuclear morphology in hematoxylincounterstained sections or their superficial location.

At 2 weeks after tracer, ${ }^{3} \mathrm{H}$-thy/OMP-labeled neurons can be identified on both sides, although they are much less frequent on the ablated side (Fig. 14). Conversely, ${ }^{3} \mathrm{H}$-thy/GAP-43-labeled cells are rare at 2 weeks, having declined in number on both sides by roughly $90 \%$ in the interval between $5 \mathrm{~d}$ and 2 weeks after tracer (Fig. 14, Table 2). Both results indicate that there is no absolute block to the maturation of olfactory neurons within that time period. However, the composition of the 2-weekold population differs with respect to immunochemical maturation between the ablated and control sides. For example, at 2 weeks after tracer ${ }^{3} \mathrm{H}$-thy/GAP-43-labeled neurons are greater in number on the ablated side by roughly 2.7 -fold as compared to control (Table 2). In addition, they constitute a greater percentage of the 2-week-old neuronal cohort on the ablated side, accounting for roughly $40 \%$ of the labeled cells on the ablated side as compared to $12 \%$ on control (Table 2 ). The vast majority 
Table 2. GAP-43/3 H-thy double-labeled cells at $5 \mathrm{~d}$ and 2 weeks of neuronal age

\begin{tabular}{|c|c|c|c|}
\hline & $\begin{array}{l}\text { Double-labeled } \\
\text { neurons at } 5 \mathrm{~d} \\
\text { post tracer } \\
\text { (per } \mathrm{mm} \text { ) }\end{array}$ & $\begin{array}{l}\text { Double-labeled } \\
\text { neurons at } 2 \\
\text { weeks } \\
\text { post tracer } \\
\text { (per mm) }{ }^{a}\end{array}$ & $\begin{array}{l}{ }^{3} \mathrm{H} \text {-thy- } \\
\text { labeled } \\
\text { cells (tolal) } \\
\text { at } 2 \text { weeks } \\
\text { post } \\
\text { tracer } \\
(\text { per } \mathrm{mm})^{a}\end{array}$ \\
\hline Ablated side ${ }^{b}$ & $\begin{array}{l}33.6 \pm 3.4 \\
(n=3)\end{array}$ & $\begin{array}{l}2.3 \pm 0.3 \\
(n=3)\end{array}$ & $\begin{array}{l}5.5 \pm 1.2 \\
(n=3)\end{array}$ \\
\hline Control side ${ }^{b}$ & $15.8 \pm 2.2$ & $0.9 \pm 0.1$ & $7.5 \pm 0.6$ \\
\hline Ablated/control & 2.1 & 2.6 & 0.7 \\
\hline
\end{tabular}

${ }^{a}$ Both of these measures were determined on the same scctions as describcd in Materials and Methods.

"For each case, labeled cells were counted on both the ablated and control sides of the sante sections as described in Materials and Methods.

of the remaining 2-week-old cells are mature (i.e., OMP-expressing) neurons on both sides; therefore, 2-week-old mature neurons are fewer in absolute number and are a smaller percentage of the total in the targetless epithelium.

On first glance, both the preservation of relatively greater numbers of 2-week-old immature neurons and the smaller perccntagc of the 2-week-old population that is mature on the ablated side might be considered evidence that neuronal maturation is delayed in the absence of the bulb, particularly in the face of a more rapid fall in neuronal number on the ablated side between $5 \mathrm{~d}$ and 2 weeks of neuronal age (see the first section of the Results). However, the 2.7 -fold greater number of ${ }^{3} \mathrm{H}$ thy/GAP-43-labeled neurons on the ablated side at 2 weeks parallels the 2.3-fold increase in the rate of neurogenesis in the targetless epithelium that was described earlier in the Results. Therefore, the larger size of the neuronal cohort born on the ablated side can account for the larger number of 2-week-old immature neurons on that side, without invoking a delay in maturation as the explanation for this increase. The lesser percentage of 2-week-old OMP-expressing neurons on the ablated side is more likely an indication that mature neurons die preferentially and cannot be considered unequivocal proof of delayed maturation.

The data on GAP-43 expression as a function of neuronal age suggest that the absence of the target has no identifiable effect on the time during a neuron's life-span when it expresses GAP-43. A second means of assessing the effect of bulbectomy on neuronal differentiation is to compare the relative rates of basal cell proliferation on the two sides to the difference in the number of GAP-43-containing neurons, since finding disproportionately more immature neurons than proliferating basal cells on the ablated side would be evidence that neuronal differentiation is delayed in the absence of the normal target. We demonstrated earlier in the Results that a greater number of basal cells are proliferating on the ablated side by slightly more than twofold. We have found that the relative difference in the number of immature neurons (i.e., GAP-43 labeled) on the two sides is about the same as the difference in the rate of basal cell proliferation. For cxamplc, for the threc cascs killed $2 \mathrm{hr}$ aftcr tracer in which GAP-43-labeled neurons and proliferating basal cells were counted on adjacent series of sections (see Materials and Methods), the ratio of anti-GAP-43-stained cells on the ablated versus the control side was $2.4 \pm 0.5$; by comparison,
Table 3. The increase in GAP-43-labeled neurons versus the enhancement of basal cell proliferation

\begin{tabular}{llll} 
Animal $^{u}$ & Analysis $^{j}$ & $\begin{array}{l}\text { Thy- } \\
\text { labeling } \\
(\mathrm{Abl} / \mathrm{Ctl})^{c}\end{array}$ & $\begin{array}{l}\text { GAP-43- } \\
\text { labeling } \\
(\mathrm{Abl} / \mathrm{Ctl})^{c}\end{array}$ \\
\hline JS284 & Adjacent series & 2.24 & 2.25 \\
JS285 & Adjacent series & 2.61 & 2.95 \\
JS286 & Adjacent series & 1.81 & 2.04 \\
JS286 & Same sections & 1.96 & 2.03
\end{tabular}

${ }^{a}$ For each case, the animal was killed $2 \mathrm{hr}$ after the injection of ${ }^{3} \mathrm{H}$-thy and labeled cells were counted as described in Materials and Methods.

${ }^{b}$ The numbers of ${ }^{3} \mathrm{H}$-thy- or GAP-43-labeled cells were determined either on adjacent series of sections if the GAP-43 staining was visualized using fluoresceinated avidin or on the same sections if the GAP-43 staining was visualized using avidin-biotinylated HRP and diaminobenzidine, as described in Materials and Methods.

c For both ${ }^{3} \mathrm{H}$-thy and GAP-43, the labeling index was determined as described in Materials and Methods for each side separately, and the ratio of the ablated to the control side was then calculated.

the ratio of autoradiographically labeled basal cells on the two sides was $2.2 \pm 0.4$. The concordance in the two measures is also apparent when the results are compared on an animal-byanimal basis (Table 3 ). In addition to the analysis of adjacent sections, we directly compared, on the same sections from a single case, the number of ${ }^{3} \mathrm{H}$-thy-labcled basal cclls and antiGAP-43-stained neurons (see Materials and Methods). Nearly identical results were obtained as when the two measures were counted on adjacent sections; in this case, both the rate of basal cell proliferation on the experimental side and the number of GAP-43-stained neurons were 2.0-fold greater on the ablated side (Table 3), indicating that the accumulation of immature neurons in the targetless epithelium can be explained on the basis of the higher rate of basal cell proliferation.

Finally, we quantified the small population of neurons that coexpress GAP-43 and OMP as a means of directly evaluating the transition from GAP-43 to OMP expression in the control and targetless epithelium. On tissue sections fluorescently labeled with both antibodies, the number of GAP-43/OMP-labeled cells is greater in the targetless epithelium than in the control or in the normal (for the comparison of bulbectomized to control cpithelium, $49.3 \pm 3.1$ vs. $11.3 \pm 3.1$ double-labeled cells $/ \mathrm{mm}$, respectively; $n=3$ ). A comparison with the rate of basal cell proliferation cannot be made directly in these three cases. However, when the number of GAP-43/OMP-labeled neurons is considered as a percentage of the total number of GAP-43-labeled cells, a slightly greater percentage of GAP-43 neurons are double labeled on the bulbectomized side (14.1 \pm $0.8 \%)$ as compared to the control side $(9.4 \pm 2.6 \%)$, but the trend is not statistically significant $(t=2.30, p>0.10, n=3)$. In summary, the data on the immunohistochemical assay of GAP-43 and OMP expression provide no compelling evidence for the hypothesis that the timing or pattern of expression of these two markers is substantially altered for neurons born in the absence of their target.

\section{Discussion}

Two sets of findings emerge from our cxamination of the olfactory epithelium at long survivals after unilateral removal of the olfactory bulb. First, we have examined the life-span of neurons born in the absence of the target and compared it with the control olfactory epithelium. The data generated using ${ }^{3} \mathrm{H}$ - 

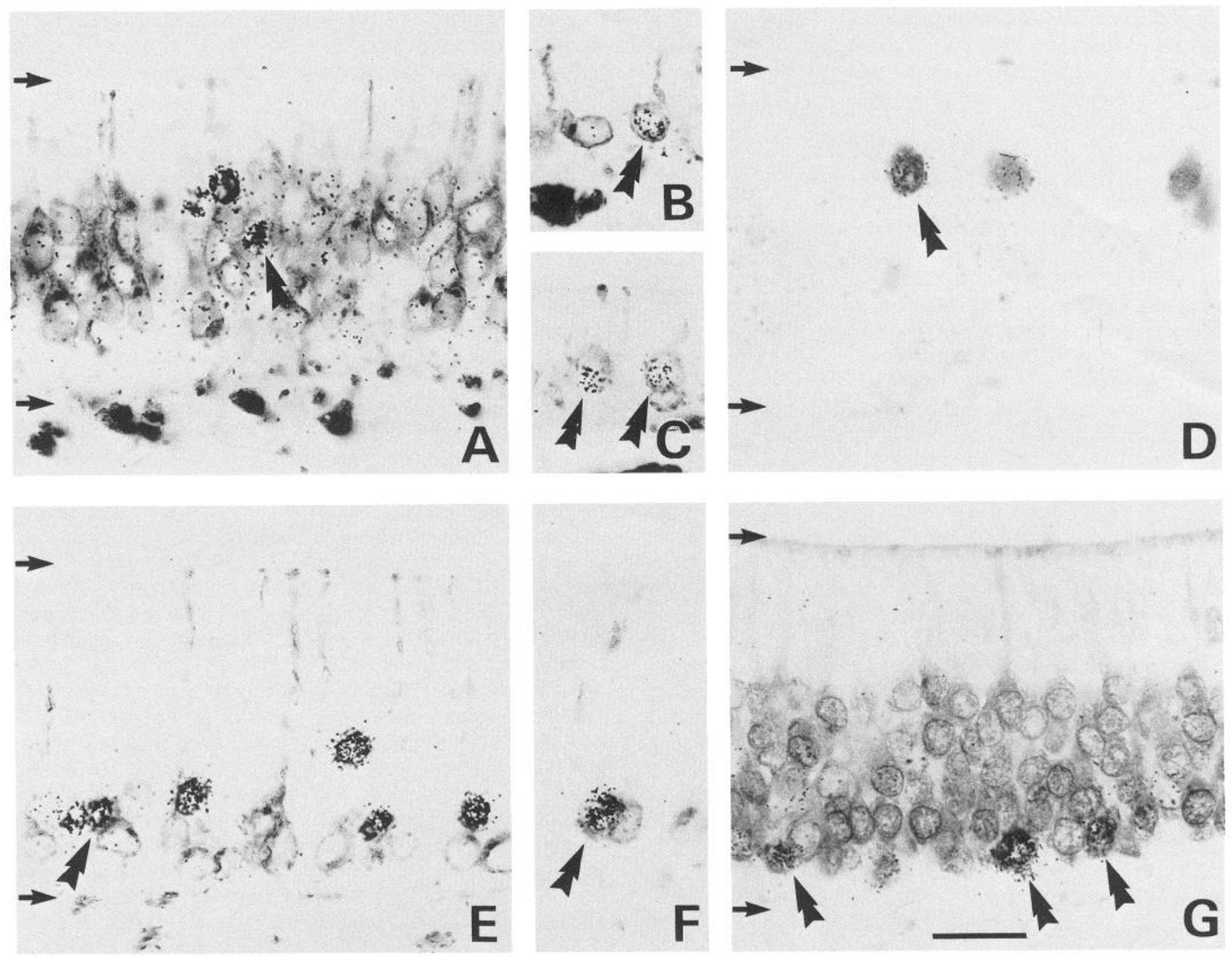

Figure 14. In the control epithelium, most 2-week-old neurons express OMP, but infrequently they contain GAP-43. In the bulbectomized epithelium, some contain GAP-43 and others express OMP. All seven micrographs are taken from the same experimental animal unilaterally bulbectomized 2 months prior to injection of ${ }^{3} \mathrm{H}$-thy and killed 2 weeks after tracer. $A-D$, Olfactory epithelium from the ablated side. $E-G$, Olfactory epithelium from the control side. $A-C, E$, and $F$ : Stained with antiserum to GAP-43. $D$ and $G$, Stained with antiserum to OMP. $A, D, E$, and $G$ : Similar locations on the nasal septum. Although more frequent on the ablated side, some 2-week-old neurons on the control side contain GAP43. Note also that the 2-week-old neurons on the control side are largely confined to the depths of the zone occupied by OMP-positive olfactory neurons. Examples of cells that are autoradiographically labeled and also stained with either the anti-GAP-43 or anti-OMP are indicated by the double arrowheads. The arrows indicate the basal lamina and the apical surface of the epithelium. In each photomicrograph, the apical surface of the epithelium is up. Note that the density of autoradiographic grains over the neurons in the bulbectomized epithelium is slightly higher than section background (which is also apparent in Fig. 4) but is insufficient for including these neurons as labeled cells. The increased grain density most likely reflects the rapid turnover and release of ${ }^{3} \mathrm{H}$-thy and its availability at low levels for reincorporation into dividing basal cells. A similar phenomenon has been noted in regions of the embryonic retina undergoing extensive cell death (Silver, 1976). Scale bar, 20 $\mu \mathrm{m}$ for $A-G$.

thy as a label indicate that neurogenesis is increased over twofold in the targetless epithelium, but that $90 \%$ of a cohort of neurons born in the olfactory epithelium on the bulbectomized side will have disappeared by 2 weeks of neuronal age (estimated as the time between injection and death). A lesser degree of loss is observed in the labeled cohort on the control side. Similar results comparing targetless and control epithelium have also been obtained by our laboratory using BrdU as tracer in a more limited set of experiments (Schwob, 1992). Moreover, degenerating axons are more frequent in the fila olfactoria on the ablated side as compared with control, which also suggests that neuronal death is accelerated in the absence of the olfactory bulb. Both data suggest that, on average, neuronal life-span is reduced in the absence of the bulb. Second, the vast majority of neurons on the ablated side are immature as defined by both ultrastructural and immunohistochemical criteria; thus, perikaryal expression of GAP-43 by olfactory neurons correlates with immature morphology (including the absence of cilia). However, the length of time during its life-span when a neuron is "immature," defined here as the time during which a neuron contains GAP-43 in its perikaryon, and the timing of the transition to the expression of OMP do not appear to be altered for neurons born in the absence of their target. These two sets of results suggest that olfactory neurons are trophically dependent on the olfactory bulb for their prolonged survival (thus resembling other types of peripheral and central neurons), but not for 
their differentiation. Based on this work, it appears that the neuronal population of the olfactory epithelium is dynamically regulated both via alterations in the rate of neuronal proliferation and in neuronal life-span. Each of these sets of results will be considered in turn.

Neuronal life-span is decreased in the absence of the bulb. Neuronal life-span can be defined either in terms of the individual neuron or in terms of the population of neurons as a whole, which can be termed "average life-span." Our discussion of the results will be limited to average life-span, for the most part. We have shown that both basal cell proliferation and neurogenesis are increased over twofold on the bulbectomized side. Likewise, other labs have shown that the basal cell proliferation is increased in rats (Carr and Farbman, 1992) and mice as a chronic consequence of ablation (Schwartz Levey et al., 1991). Despite the increased rate of production of neurons after bulbectomy, the population of neurons in the targetless epithelium is chronically reduced. Therefore, average neuronal life-span must be shorter in the absence of the bulb. That is to say, if neurons are being born at a faster rate on the bulbectomized side but are fewer in total number, they must also be dying sooner after their birth on average than in the normal or control case in order for the population to remain smaller. Similarly, the greater prevalence of degenerating axons in the fila olfactoria indicates that a greater number of neurons are dying on the ablated side at any particular point in time; since there are fewer total neurons in the targetless epithelium, the fact that more are dying than on the control side may also be interpreted as a reduction of average neuronal life-span on the ablated side. Therefore, both of these findings lead to the conclusion that olfactory neurons are trophically dependent on the bulb for survival, given that a trophic interaction can be operationally defined by the finding of deleterious effects after the removal of a target (Purves, 1988).

However, the issue of whether neuronal life-span is shorter on average as a chronic consequence of bulbectomy must be evaluated in more depth. Indeed, average life-span of the population of olfactory neurons as a whole cannot be defined solely by chasing a cohort of pulse-labeled neurons from their birth to their death, since there may be a second group of preexisting neurons, in which turnover is slower (i.e., life-span is longer) than in the cohort of olfactory neurons born at any given time in adult life (Walker et al., 1990). One way of illustrating this potential difference between newly born and preexisting populations is by analogy to human life-span; in this example, life expectancy at birth (average life-span of a newly born cohort) is less than the average total life-span of a population of middleaged adults (the preexisting population) since they, on average, exceed the figure that is characteristic of newborns. With respect to the olfactory system, average life-span could differ between the bulbectomized and control side because a second, slowlyturning-over population of neurons does not exist in the absence of the bulb. As an extreme case presented here for the purposes of discussion, it is conceivable that all of a newly born neuronal cohort may die on both sides within a relatively brief period that is roughly equivalent in both targetless and control epithelium, while the preexisting population remains more or less completely intact in the control. In this example, while average neuronal life-span would in fact be shorter in the absence of the bulb, tracking the pulse-labeled cohort, by itself, would not demonstrate this difference.

Our pulse-chase data focus directly on the average life-span of a newly born cohort in both targetless and control epithelium, but also speak to the stability of the preexisting population, so both issues will be discussed together. In the epithelium on the bulbectomized side, the ${ }^{3} \mathrm{H}$-thy data show directly that the lifespan of $90 \%$ of the neurons born at any particular point in time is less than 2 weeks. This figure may in fact be an underestimate of the percentage of neurons lost before reaching 2 weeks of neuronal age, since an additional generation or two of neurons could be born at some later time from labeled daughter cells that remain mitotically active as basal cells and contribute to the small population that remains alive at 2 weeks; at present, we have no way of estimating whether this occurs and, if so, the size of these subsequent generations. During this 2 week time period, the labeled cohort on the ablated side ascends through the neuronal zone of the epithelium in a wave, as shown by the progressively more superficial displacement of the average position of the population of labeled neurons, until at 2 weeks after tracer, the crest of this migratory wave sits just deep to the layer of supporting cells. These observations imply that the cohort of labeled neurons on the ablated side has completely, or nearly completely, replaced the neurons that were preexisting at the time of labeling during the 2 weeks following injection. An alternative explanation for the results, in which the labeled neurons migrate through a substantial population of preexisting neurons, is less likely for several reasons. First, the most mature neurons (those that contain OMP and not GAP-43) are found in the most superficial part of the neuronal zone on the ablated side, as was shown by our immunohistochemical analysis. Second, there is little vertical dispersion of the cohort at 2 weeks, that is, little lagging behind of labeled neurons in the deeper half of the epithelium on the ablated side, which would be required to renew a hypothetical population of deeply situated, longer-lived, preexisting neurons. Third, the process of neuronal migration would have to be very different on the two sides, since the labeled cohort on the control side is concentrated in the middle of the neuronal zone at this time, and is deep to unlabeled, presumably older neurons. Therefore, there is no compelling evidence that a large population of neurons older than 2 weeks is present on the ablated side. Clearly, experiments designed to assess directly the status of the preexisting population vis-à-vis a newly born cohort in targetless olfactory epithelium are necessary (and are currently underway in our laboratory). Nonetheless, the present data suggest that average life-span, and the limit on neuronal life-span as well, is about 2 weeks for all neurons in the targetless epithelium, both those neurons that are preexisting and those neurons that are newly born.

In light of the analysis on the bulbectomized side, how does neuronal life-span in the control or normal cpithclium comparc? On the control side, about $60 \%$ of the newly born cohort disappear in the period from $5 \mathrm{~d}$ to 2 weeks after injection, which is a smaller percentage than the $90 \%$ that die in the targetless epithelium. Moreover, given the twofold larger size of the cohort on the ablated side, the loss of neurons, in absolute terms, is even smaller by about two-thirds than on the ablated side. Therefore, the average life-span of the newly born neuronal cohort in the control epithelium is apparently longer than on the ablated side. In addition, the 2-week-old cohort is deep to a band of unlabeled neurons. It is likely that the unlabeled neurons that are situated more superficially in the epithelium are older than 2 weeks (i.e., older than the labeled cells deep to them) since all of them are mature, OMP-producing neurons (although 
their minimum age cannot be proven directly in the absence of experiments specifically designed to assess the preexisting population). Nonetheless, as described above, the evidence suggests that this older population is absent from the targetless epithelium. Therefore, the average life-span of the preexisting population of neurons in the control epithelium is also longer than on the ablated side.

Information about neuronal life-span in the normal (unmanipulated) rat olfactory epithelium is unfortunately limited. Preliminary evidence from our laboratory indicates that $40 \%$ of a BrdU-labeled cohort of neurons born in the epithelium of normal rats is lost between $5 \mathrm{~d}$ and 2 weeks of neuronal age; this is substantially less than the $90 \%$ loss recorded in the targetless epithelium of either ${ }^{3} \mathrm{H}$-thy (present results) or BrdU-labeled animals (Schwob, 1992). It is also less than the $53 \%$ loss from a BrdU-labeled cohort in control epithelium (Schwob, 1992). As in the control epithelium, the 2-week-old neurons in normal rats are confined to the deeper half of the neuronal zone. Moreover, we have preliminary evidence showing that at least some olfactory neurons in the normal rat epithelium live longer than 1 month, based on the persistence of rhodamine-labeled latex microspheres that have been retrogradely transported from the bulb (Schwob, unpublished observations). Our results correlate well with observations in mice indicating that some olfactory neurons have life-spans exceeding 3 months in the case of experiments utilizing retrogradely transported markers (MackaySim and Kittel, 1991 b) or up to a year in the case of experiments utilizing ${ }^{3} \mathrm{H}$-thy (Hinds et al., 1984), even though some of the apparently long-lived thymidine-labeled neurons could potentially derive from labeled basal cells that become quiescent for a prolonged period of time. Finally, previously published analyses of neuronal life-span in epithelium from normal (unmanipulated) mice indicate that the number of ${ }^{3} \mathrm{H}$-thy-labeled olfactory neurons may actually increase somewhat between 1 and 2 weeks of neuronal age, although the reported increase does not appear to be statistically significant (Mackay-Sim and Kittel, $1991 \mathrm{a})$. For the same reasons as outlined above during the comparison of control and targetless epithelium, it is likely that average neuronal life-span of a newly born cohort in the normal epithelium is longer than in the epithelium on either the ablated or control sides.

We would argue that the convergence of evidence from the comparison of targetless with control and normal epithelium suggests that average neuronal life-span is substantially shorter for olfactory neurons born in the absence of their target, despite the fact that we cannot define precisely how long life-span is in either normal or control epithelium. Therefore, olfactory neurons, like other neurons, are trophically dependent on contact with their target for their prolonged survival.

A subsidiary issue arising from these experiments derives from our comparison of the unoperated side of a bulbectomized animal with normal, age-matched epithelium. We find that basal cell proliferation in the control epithelium is roughly 1.25 -fold greater than normal and, as suggested by the preliminary results described immediately above, that death in a newly born neuronal cohort is somewhat accelerated on the unoperated side of a unilaterally bulbectomized rat as compared to normal, otherwise unmanipulated animals. Both of these indicate that the unoperated side of unilaterally bulbectomized rat is not equivalent to normal. The changes in the control epithelium are not likely to be a consequence of damage to the bulb or axons of the olfactory nerve on the unoperated side at the time of surgery for two reasons. First, the projection of the epithelium onto the bulb in mammals is strictly unilateral. Second, the status of the bulb and the projection of the epithelium onto the bulb via the olfactory nerve were evaluated on the unoperated side with conventional counterstains and by GAP-43 and OMP immunohistochemistry to rule out any unintended damage. The effects on proliferation and neuronal survival were observed in animals in which there was no apparent damage to either the olfactory nerve layer or underlying olfactory bulb, and in which the dura between the intact bulb and the ablation cavity was demonstrably intact.

Why then is neuronal death between $5 \mathrm{~d}$ and 2 weeks of neuronal age accelerated on the unoperated side of a unilaterally bulbectomized rat in the absence of any damage to the contralateral bulb? The apparent trophic dependency of olfactory neurons might also be a way to account for the acceleration of neuronal death in the control epithelium. In this case, the increased proliferation of basal cells in the control epithelium as comparcd to normal may bc both causc and cffect. Although the control bulb is grossly intact and normally innervated by the epithelium, the increased numbers of neurons that are being born on the control side may exceed the trophic capacity of the bulb, either because the bulb's capacity remains normal (but would need to increase to meet the larger demand) or because it is compromised as a consequence of damage to the central olfactory system on the bulbectomized side that disrupts direct and indirect crossed input to the control bulb from the ablated side (Haberly and Price, 1978; Carr and Farbman, 1992). As a result of either mechanism, death is accelerated in the control epithelium as compared to normal. Since retrograde neuronal degeneration is likely to be a stimulus for basal cell proliferation, as shown by the acute increase in proliferation after bulb ablation (Schwartz Levey et al., 1991), the acceleration of neuronal death and the parallel increase in the rate of basal cell prolifcration in the control epithclium could maintain cach other. However, if the trophic capacity of the remaining bulb is unaffected, then the initiation of this cycle would require some means of increasing the rate of basal cell proliferation in the control epithelium, such as the release of some form of growth factor into the systemic circulation as a consequence of the destruction of a bulb that stimulates neurogenesis on the unoperated side. Although these possibilities are clearly hypothetical, it may be possible to assess during the first week after bulbectomy whether the stimulation of neurogenesis on the control side precedes or follows the increase in neuronal death on that side; it appears that both measures are aready increased by the end of the first postlesion week (Carr and Farbman, 1992). Despite our inability to account fully for differences between normal and control, it is important to note that the acceleration of neuronal death in the control epithelium is in no way inconsistent with our conclusion that olfactory ncurons arc trophically dependent on the bulb for their prolonged survival and may indeed be a further example of this dependency.

Although immature neurons predominate, the course of neuronal differentiation is largely unaffected by the absence of the bulb. Our results demonstrate that the majority of olfactory neurons in the targetless epithelium fail to generate a full complement of cilia and that most neurons contain GAP-43 in their perikarya; therefore, the epithelium is largely populated with neurons that are immature both by ultrastructural criteria and in terms of their pattern of protein expression. The accumulation of GAP-43-labeled olfactory neurons and the depletion of OMP- 
labeled neurons on the ablated side might initially lead to the suggestion that the absence of the target has delayed or somehow altered neuronal differentiation, thereby causing immature neurons to accumulate. However, since neurogenesis is increased in the targetless epithelium, the greater number of immature neurons might simply reflect the rate of neurogenesis and does not necessarily imply that differentiation is delayed. Similarly, since average neuronal life-span is shorter on the ablated side, the decreased number of mature neurons might simply reflect the acceleration of neuronal death and also does not necessarily imply that differentiation is delayed. Indeed, there are three lines of evidence to suggest that neuronal differentiation is unaffected by bulbectomy up to the time when neurons die.

First, the time course of differentiation was not substantially delayed. When GAP-43 expression was compared with neuronal age (as defined by the passage of time since the injection of the ${ }^{3}$ II-thy), it was directly shown to be limited to a relatively short period after a neuron leaves the mitotic cycle. That is, virtually all 5-d-old neurons contain GAP-43 but by 2 weeks of neuronal age, the vast majority of neurons have lost that capacity and express OMP instead (confirming previous results in mice; $\mathrm{Mi}$ ragall and Monti Graziadei, 1982), or they have disappeared. As such, our observations confirm and extend previously published reports that used largely immunohistochemical means of assessing the differentiation of neurons in the absence of the bulb (Monti Graziadei, 1983; Morrison and Graziadei, 1983; Monti Graziadei and Morrison, 1988; Verhaagen et al., 1990).

Second, the absence of the target did not prevent a substantial degree of neuronal maturation. Some olfactory neurons in the targetless epithelium do generate a normal or near normal number of cilia (although our analysis could not document whether the total ciliary length elaborated by these neurons is normal). Likewise, some OMP-positive neurons are observed in the targetless epithelium, although these are limited in number (as originally described and similarly interpreted by Monti Graziadei, 1983). Furthermore, based on the analysis of doubly immunostained sections, many of these OMP-expressing neurons do not contain GAP-43 in their cell bodies, which provides a further indication of maturation.

Third, the absence of the target does not expand the population of immature neurons out of proportion to the degree to which production of neurons is greater on the ablated side. For example, in the targetless epithelium, the total number of immature neurons (i.e., those that contain GAP-43), the number of immature neurons that are of a defined age (i.e., 2 weeks after becoming postmitotic), and the number of immature neurons that are of a defined stage (i.e., concurrent staining with both anti-OMP and GAP-43) are all roughly twofold greater on the ablated side, and thus parallel to the twofold enhancement of neurogenesis on this side relative to control. Since any delay in differentiation would be expected to expand the population of immature neurons beyond the degree that reflects enhanced neurogenesis, we favor the interpretation that the larger pool of immature neurons is most likely due to the increased production of neurons.

Therefore, we would hypothesize that olfactory neurons, once born, differentiate up to or shortly beyond the stage characterized by the onset of OMP expression, the elaboration of cilia, and the disappearance of perikaryal GAP-43, according to a schedule that is largely or wholly independent of the presence of the olfactory bulb. In this they resemble other developing neuronal populations, such as the chick ciliary ganglion and the lateral motor column where neurons appear to differentiate normally until the period of cell death (reviewed by Purves, 1988). Apparently, neuronal maturation is not induced by the olfactory bulb, but rather the population of mature neurons is stabilized in number via the trophic support supplied by the target. It remains entirely possible that other, more subtle features of olfactory neuronal differentiation, such as GAP-43 gene expression or the timing of expression of components of the sensory transduction process (Jones and Reed, 1989; Bakalyar and Reed, 1990; Dhallan et al., 1990; Buck and Axel, 1991), may show differences between olfactory neurons born in the absence versus presence of the olfactory bulb. However, the present data support the conclusion that differentiation, up to the point in time that olfactory neurons die, is independent of the bulb.

When during their life-span do olfactory neurons die in the absence of the bulb? In other neural systems where trophic starvation causes neuronal death, for example, in the case of the $\operatorname{limb}$ bud and lateral motor column in the spinal cord of the chick, death occurs after the neurons have reached the target or after they would normally have reached the target if it had not been destroyed (reviewed by Purves, 1988). Unfortunately, the time point during their life when olfactory neurons establish axonal contact with the olfactory bulb has not yet been determined. However, it is worth noting that in normal animals the axons of a substantial number and proportion of GAP-43-containing olfactory neurons have reached the bulb, based on our preliminary experiments combining GAP-43 immunohistochemistry with the retrograde transport of latex microspheres from the olfactory bulb (Schwob, 1991). Since the transition from GAP-43 to OMP expression mostly takes place between $5 \mathrm{~d}$ and 2 weeks, axonal contact with the bulb is probably established before 2 weeks of neuronal age. Therefore, the occurrence of neuronal death on the ablated side between $5 \mathrm{~d}$ and 2 weeks of neuronal age seems to be roughly coincident with the normal time that axons arrive at the olfactory bulb.

In addition, our data do suggest that, in the absence of trophic support from the bulb, neuronal death is temporally associated with, or more likely occurs shortly after the transition from, GAP-43 to OMP expression. First, the timing of death and differentiation is roughly the same: between $5 \mathrm{~d}$ and 2 weeks of neuronal age most neurons in the targetless epithelium either make the transition from perikaryal expression of GAP-43 to expression of OMP, or they disappear. The same occurs in the epithelium on the control side. Second, at 2 weeks of age, immature neurons are relatively well preserved and mature neurons are disproportionately reduced on the ablated side. On both ablated and control sides, 2-week-old neurons that contain GAP43 are only about $5 \%$ of the number that contain GAP-43 at 5 d of neuronal age. Nonetheless, GAP-43-containing neurons make up a larger percentage of the group of 2-week-old cells on the ablated side than on the control side ( $43 \%$ vs. $12 \%$, respectively); conversely, OMP-containing neurons are a smaller percentage of the 2-week-old population in the targetless epithelium. If age were the only factor that determined when a neuron died in the absence of the bulb, the percentages of 2-week-old OMP and GAP -43 neurons would be the same on the two sides. Third, the presence of a significant population of OMP-positive neurons in the bulbectomized epithelium indicates that death is deferred until OMP appears, for at least some of the neurons. Hence, the timing of neuronal death may be linked both with the time when olfactory axons would normally arrive at the bulb, as would be expected from the trophic dependency of these 
neurons on the bulb for their survival, and with the time of transition from GAP-43 to OMP expression. The reason for the association between stage of maturation and neuronal death is not immediately obvious. Clearly, further experimentation will be required to understand these associations better.

Despite the fact that most neuronal death takes place between $5 \mathrm{~d}$ and 2 weeks of neuronal age, it is important to note that some neuronal death precedes this period. For example, labeled pyknotic neurons can be observed $5 \mathrm{~d}$ after the injection of ${ }^{3} \mathrm{H}$ thy at a frequency of about $1 \%$ of the total number of labeled cells (data not shown). They are slightly more frequent on the bulbectomized side than in the control epithelium. However, at this survival time the small increase in ${ }^{3} \mathrm{H}$-thy-labeled pyknotic neurons on the ablated side is not out of proportion to the greater total number of labeled neurons at $5 \mathrm{~d}$ on that side, which contrasts with the massive loss of labeled neurons between $5 \mathrm{~d}$ and 2 weeks and the severe depletion of the population of OMP-positive neurons in the targetless epithelium. Other laboratories have also observed greater numbers of pyknotic cells that are 1 week of neuronal age or less in the targetless epithelium (Carr and Farbman, 1992). Both the exact magnitude of this very early neuronal death and its relationship to the trophic effects that we are observing will require further analysis.

The dynamic regulation of neuronal birth and death in the olfactory epithelium. The present demonstration that the olfactory bulb exerts a trophic influence on the survival of its afferent population should be considered within the context of what has been previously shown regarding neurogenesis and neuronal turnover in the olfactory epithelium. The analysis of other neural systems has led to the hypothesis that trophic interactions serve to match the size of afferent and target populations and, further, to correct any errors in development of axonal projections, thereby ensuring reproducible nervous system functioning across the members of a species without the necessity of precise genetic control (Purves, 1988). In the olfactory epithelium, the continuation of neurogenesis throughout the life of the animal additionally complicates the regulation of neuronal number. By comparison, in non-neural populations, cell number is controlled by alterations in the rate of stem cell division, for the most part; for example, in many epithelia, an increase in stem cell proliferation accompanies wound healing and epithelial reconstitution (Cotsarellis et al., 1989; Inayama et al., 1989). In the olfactory epithelium, adjustments in the rate of basal cell proliferation would potentially provide a means of regulating the size of the olfactory neuronal population, and this rate does vary with the demand for replacement neurons. For example, basal cell proliferation, and more specifically the proliferation of the population of basal cells that do not express keratin, is markedly enhanced at short survivals after bulb ablation or olfactory nerve section, presumably in response to the retrograde neuronal degeneration induced by the manipulation (Camara and Harding, 1984; Schwartz Levey et al., 1991). Likewise, basal cell proliferation is increased over 10 -fold during the recovery of the epithelium from direct injury produced by methyl bromide exposure (Hurtt et al., 1988; Schwob and Youngentob, 1991, and unpublished observations).

Although neurogenesis is regulated in the olfactory epithelium (at least in part by the presence or absence of the bulb), our work shows that an additional step controls olfactory neuronal number, namely, the contact with the bulb. The likely reason for this extra mechanism, in common with other neurons, is the general need for a balance between afferent populations and targets that cannot easily be struck by precisely controlling the neurogenic process by feedback at the epithelial level.

In conclusion, the sum of available evidence suggests that the size of the population of olfactory neurons is regulated in two ways. First, from our work presented here, neuronal life-span can be cut short when neurons fail to contact the olfactory bulb either because it has been ablated or perhaps, by extension to the neuronal loss encountered in the control epithelium, because they are unable to achieve adequate trophic support from a grossly intact but fully innervated bulb. Second, neuronal death induced by this trophic failure or direct neuronal injury would reflexively increase the numbers of newly postmitotic ncurons by enhancing basal cell proliferation. This twofold mechanism would participate in the regulation of neuronal number and help match the size of the afferent population to target availability whether life-span is regulated by extrinsic injury, to which olfactory neurons are particularly susceptible by virtue of their direct contact with the environment (Farbman, 1990), or whether olfactory neurons additionally have a fixed, intrinsic limit to their life-span (Graziadei and Monti Graziadei, 1979). Moreover, this type of mechanism brings the olfactory epithelium more in line with what is known of other neural systems and their development, including recent reports indicating that the proliferation rate of neuroepithelial cells from the developing brain and retina are susceptible to change by exposure to growth factors and other extrinsic stimuli (Cattaneo and McKay, 1990; DiCiccio-Bloom et al., 1990; Anchan et al., 1991; Gao et al., 1991). Accordingly, the olfactory epithelium retains its stature as a uniquely useful model system in which many of the events of neural embryogenesis are recapitulated on a daily basis throughout the life of the animal.

\section{References}

Anchan RM, Reh TA, Angello J, Balliet A, Walker M (1991) EGF and TGF- $\alpha$ stimulate retinal neuroepithelial cell proliferation in vitro. Neuron 6:923-936.

Bakalyar HA, Reed RR (1990) Identification of a specialized adenylyl cyclase that may mediate odorant detection. Science 250:1403-1406.

Berger B (1971) Etude ultrastructurale de la degenerescence Walleriene experimentale d'un nerf entierement amyelinique: le nerf olfactif. I. Modifications axonales. J Ultrastruct Res 37:105-118.

Boswald M, Harasim S, Maurer-Schultze B (1990) Tracer dose and availability time of thymidine and bromodeoxyuridine: application of bromodeoxyuridine in cell kinetic studies. Cell Tissue Kinet 23: 169-181.

Buck L, Axel R (1991) A novel multigene family may encode odorant receptors: a molecular basis for odor recognition. Cell 65:175-187.

Calof AL, Chikaraishi DM (1989) Analysis of neurogenesis in a mammalian neuroepithelium: proliferation and differentiation of an olfactory neuron precursor in vitro. Neuron 3:115-127.

Camara CG, Harding JW (1984) Thymidine incorporation in the olfactory epithelium of mice: early exponential response induced by olfactory neurectomy. Brain Res 308:63-68.

Carr VMM, Farbman AI (1992) Ablation of the olfactory bulb upregulates the rate of neurogenesis and induces precocious cell death in olfactory epithelium. Exp Neurol 115:55-59.

Cattaneo E, McKay RG (1990) Proliferation and differentiation of neuronal stem cells regulated by nerve growth factor. Nature 347 : 762-765.

Chuah MI, Farbman AI (1983) Olfactory bulb increases marker protein in olfactory receptor cells. J Neurosci 3:2197-2205.

Chuah MI, Farbman AI, Menco BPM (1985) Influence of olfactory bulb on dendritic knob density of rat olfactory receptor neurons in vitro. Brain Res 338:259-266.

Cook RD, Ghetti B, Wisniewski HM (1974) The pattern of Wallerian degeneration in the optic nerve of newborn kittens: an ultrastructural study. Brain Res 75:261-275.

Costanzo RM, Graziadei PPC (1983) A quantitative analysis of changes 
in the olfactory epithelium following bulbectomy in hamster. J Comp Neurol 215:370-381.

Cotsarelis G, Cheng SZ, Dong G, Sun TT, Lavker RM (1989) Existence of slow-cycling limbal epithelial basal cells that can be preferentially stimulated to proliferate: implications on epithelial stem cells. Cell 57:201-209.

Curtis R, Hardy R, Reynolds R, Spruce BA, Wilkin GP (1991) Downregulation of GAP-43 during oligodendrocyte development and lack of expression by astrocytes in vivo: implications for macroglial differentiation. Eur J Neurosci 3:876-886.

Cuschieri A, Bannister LH (1975) The development of the olfactory mucosa in the mouse: electron microscopy. J Anat 119:471-498.

Del Cerro MP, Snider RS (1968) Studies on the developing cerebellum. Ultrastructure of the growth cones. J Comp Neurol 133:341-362.

Denham S (1967) A cell proliferation study of the neural retina in the two-day rat. J Embryol Exp Morphol 18:53-66.

Dhallan RS, Yau KW, Schrader KA, Reed RR (1990) Primary structure and functional expression of a cyclic nucleotide-activated channel from olfactory neurons. Nature 347:184-187.

DiCicco-Bloom E, Townes-Anderson E, Black IB (1990) Neuroblast mitosis in dissociated culture: regulation and relationship to differentiation. J Cell Biol 110:2073-2086.

Farbman AI (1990) Olfactory neurogenesis: genetic or environmental controls? Trends Neurosci 13:362-365.

Fox GQ, Pappas GD, Purpura DP (1976) Fine structure of growth cones in medullary raphe nuclei in postnatal cat. Brain Res 101:411425.

Frisch D (1967) Ultrastructure of the mouse olfactory mucosa. Am J Anat 121:87-120.

Gao W-Q, Heintz N, Hatten ME (1991) Cerebellar granule cell neurogenesis is regulated by cell-cell interactions in vitro. Neuron 6:705715.

Graziadei PPC (1974) The olfactory organ of vertebrates: a survey. In: Essays on structure and function in the nervous system (Bellairs R, Gray EG, eds), pp 191-222. London: Clarendon.

Graziadei PPC, Monti Graziadei GA (1978) Continuous nerve cell renewal in the olfactory system. In: Handbook of sensory physiology, Vol IX, Development of sensory systems (Jacobson M, ed), pp 5583. Berlin: Springer.

Graziadei PPC, Monti Graziadei GA (1979) Neurogenesis and neuron regeneration in the olfactory system of mammals. I. Morphological aspects of differentiation and structural organization of the olfactory sensory neurons. J Neurocytol 8:1-18.

Graziadei PPC, Monti Graziadei GA (1980) Neurogenesis and neuron regeneration in the olfactory system of mammals. III. Deafferentation and reinnervation of the olfactory bulb following section of the fila olfactoria in rat. J Neurocytol 9:145-162.

Haberly LB, Price JL (1978) Association and commissural fiber systems of the olfactory cortex of the rat. II. Systems originating in the olfactory peduncle. J Comp Neurol 181:781-808.

Hinds JW, Hinds PL, McNelly NA (1984) An autoradiographic study of the mouse olfactory epithelium: evidence for long-lived receptors. Anat Rec 210:375-383.

Hurtt ME, Thomas DA, Working PK, Monticello TM, Morgan KT (1988) Degeneration and regeneration of the olfactory epithelium following inhalation exposure to methyl bromide: pathology, cell kinetics and olfactory function. Toxicol Appl Pharmacol 94:311-328.

Inayama Y, Hook GE, Brody AR, Jetten AM, Gray T, Mahler J, Nettesheim $\mathbf{P}$ (1989) In vitro and in vivo growth and differentiation of clones of tracheal basal cells. Am J Pathol 134:539-549.

Jones DT, Reed RR (1989) $G_{\text {olf }}$ : an olfactory neuron specific-G protein involved in odorant signal transduction. Science 244:790-795.

Kriss JP, Revesz L (1962) The distribution and fate of bromodeoxyuridine and bromodeoxycytidine in the mouse and rat. Cancer Res 22: 254-265.

Le Gros Clark WE (1951) The projection of the olfactory epithelium on the olfactory bulb in the rabbit. J Neurol Psychiatry 14:1-10.

Mackay-Sim A, Kittel P (1991a) Cell dynamics in the adult mouse olfactory epithelium: a quantitative autoradiographic study. J Neurosci 11:979-984.

Mackay-Sim A, Kittel PW (1991b) On the life span of olfactory receptor neurons. Eur J Neurosci 3:209-215.

Margolis FL (1985) Olfactory marker protein: from PAGE band to cDNA clone. Trends Neurosci 8:542-546.

Meiri KF, Bickerstaff LE, Schwob JE (1991) Monoclonal antibodies show that kinase $\mathrm{C}$ phosphorylation of GAP-43 during axonogenesis in both spatially and temporally restricted in vivo. J Cell Biol 112: 991-1005.

Menco BM (1989) Electron-microscopic demonstration of olfactorymarker protein with protein G-gold in freeze-substituted, Lowicryl K11M-embedded rat olfactory-receptor cells. Cell Tissue Res 256: 275-281.

Menco BM, Farbman AI (1985) Genesis of cilia and microvilli of rat nasal epithelia during prenatal development. J Cell Sci 78:283-310.

Miller MW, Nowakowski RS (1988) Use of bromodeoxyuridine-immunohistochemistry to examine the proliferation, migration and time of origin of cells in the central nervous system. Brain Res 457:44-52.

Miragall F, Monti Graziadei GA (1982) Experimental studies on the olfactory marker protein. II. Appearance of the olfactory marker protein during differentiation of the olfactory sensory ncurons of mousc: an immunohistochemical and autoradiographic study. Brain Res 239: 245-250.

Monti Graziadei GA (1983) Experimental studies on the olfactory marker protein. III. The olfactory marker protein in the olfactory neuroepithelium lacking connections with the forebrain. Brain Res 262:303-308.

Monti Graziadei GA, Graziadei PPC (1979) Neurogenesis and neuron regeneration in the olfactory system of mammals. II. Degeneration and reconstitution of the olfactory sensory neurons after axotomy. $J$ Neurocytol 8:197-213.

Monti Graziadei GA, Morrison EE (1988) Experimental studies on the olfactory marker protein. IV. Olfactory marker protein in the olfactory neurons transplanted within the brain. Brain Res 445:401406.

Moran DT, Rowley JC III, Jafek BW (1982) Electron microscopy of human olfactory epithelium reveals a new cell type: the microvillar cell. Brain Res 253:39-46.

Morrison EE, Graziadei PPC (1983) Transplants of olfactory mucosa in the rat brain. Brain Res 279:241-245.

Moulton DG, Celebi G, Fink RP (1970) Olfaction in mammals-two aspects: proliferation of cells in the olfactory epithelium and sensitivity to odours. In: Taste and smell in vertebrates (Wolstenholme GEW, Knight J, eds), pp 241-252. London: Churchill.

Nowakowski RS, Rakic P (1974) Clearance rate of exogenous ${ }^{3} \mathrm{H}$ thymidine from the plasma of Rhesus monkey. Cell Tissue Kinet 7: 189-194.

Purves D (1988) Body and brain. A trophic theory of neural connections. Cambridge: Harvard UP.

Reese TS (1965) Olfactory cilia in the frog. J Cell Biol 25:209-230.

Rogers AW (1979) Techniques in autoradiography, 3d ed. Amsterdam: Elsevier.

Rowley JC III, Moran DT, Jafek BW (1989) Peroxidase backfills suggest the mammalian olfactory epithelium contains a second morphologically distinct class of bipolar sensory neuron: the microvillar cell. Brain Res 502:387-400.

Schwartz Levey MA, Chikaraishi DM, Kauer IS (1991) Characterization of potential precursor populations in the mouse olfactory epithelium using immunocytochemistry and autoradiography. J Neurosci 11:3556-3564.

Schwob JE (1991) Stages in the differentiation of olfactory sensory neurons. Chem Senses 16:579.

Schwob JE (1992) The biochemistry of olfactory neurons: stages of differentiation and neuronal subsets. In: The science of olfaction (Serby $\mathrm{ML}$, Chodor KL, eds), in press. New York: Springer.

Schwob JE, Szumowski KE (1989) Olfactory sensory neurons are trophically dependent on the olfactory bulb for their prolonged survival. Soc Neurosci Abstr 15:749.

Schwob JE, Youngentob SL (1991) Reconstitution of the olfactory epithelium and reinnervation of the olfactory bulb after methyl bromide lesions. Soc Neurossi Abstr 17:635.

Schwob JE, Szumowski KE, Brodie KB (1988) Differentiation of olfactory sensory neurons in the absence of their postsynaptic target. Soc Neurosci Abstr 14:1169.

Silver J (1976) A study of ocular morphogenesis in the rat using $\left[{ }^{3} \mathrm{H}\right]$ thymidine autoradiography: evidence for thymidine recycling in the developing retina. Dev Biol 49:487-495.

Skalko RG, Packard DS Jr, Schwendimann RN, Raggio JF (1971) The teratogenic response of mouse embryos to 5-bromodeoxyuridine. Teratology 4:87-94.

Skoff RP, Hamburger V (1974) Fine structure of dendritic and axonal 
growth cones in embryonic chick spinal cord. J Comp Neurol 153: $107-148$

Verhaagen J, Oestreicher AB, Gispen WH, Margolis FL (1989) The expression of the growth associated protein $\mathrm{B} 50 / \mathrm{GAP} 43$ in the olfactory system of neonatal and adult rats. J Neurosci 9:683-691.

Verhaagen J, Oestreicher AB, Grillo M, Khew-Goodall Y-S, Gispen WH, Margolis FL (1990) Neuroplasticity in the olfactory system: differential effects of central and peripheral lesions of the primary olfactory pathway on the expression of B-50/GAP43 and the olfactory marker protein. J Neurosci Res 26:31-44.
Walker DG, Breipohl W, Simon-Taha A, Lincoln D, Lobie PE, Aragon JG (1990) Cell dynamics and maturation within the olfactory epithelium proper of the mouse-a morphometric analysis. Chem Senses 15:741-753.

Westrum LE (1980) Alterations in axons and synapses of olfactory cortex following olfactory bulb lesions in newborn rats. Anat Embryol 160:153-172. 